\title{
Cultural Turn in Geography and its Impacts on the Field of Political Geography
}

\section{ART ICLE INFO}

\section{Article Type}

Original Research

\section{Authors}

Mirahmadi F.S.* PhD,

Ahmadi S.A. ${ }^{1}$ PhD
How to cite this article Mirahmadi F.S, Ahmadi S.A. Cultural Turn in Geography and its Impacts on the Field of Politi-cal Geography. Geographical Researches Quarterly Journal. 2018;33 (3):58-72.

\begin{abstract}
A B S T R A C T
Introduction and Background Cultural turn is a collection of intellectual development that from the late 1980s has expanded the scope of geography and it has led to the centering of cultural issues in human geography. There are two types of cultural turn: the first one refers to theorizing about the world, while the second one is more philosophical and abstract. In second type culture is regarded as "as a way of thinking and knowing".

Aims Considering the importance of cultural turn for the field of political geography, and this fact that this issue has not been touched upon in Persian, the present paper addresses the impacts of cultural turn on the field of political geography.

Methodology The present study uses "analytic-descriptive" approach as it methodology. Due to the nature of the topic, data was collected through library and internet research. The required information was extracted from books and papers and categorized, and then was analyzed qualitatively.

Conclusion In political geography affected by culture, "political" has a meaning beyond the conventional meaning of official politics. In this regard political geography recognizes and represents the mutual effects of cultural "signs" and "symbols" on one hand, and "political acts" on the other. In this regard, in particular, the focus is on "meaning" and the struggle for meaning and discourse. The result of paper shows that cultural turn has had three main impacts on political geography. The first one is reformulation of the concepts and subjects of political geography from a cultural lens. The second impact is focus on new issues, such as cultural politics, which were not taken into consideration before 1980s. The third effect is attention to culture from the viewpoint of generating knowledge of political geography. In this respect, the social construction of knowledge by social groups in special time-place contexts and cultures is criticized and analyzed. In other words, political geography is evaluated on the basis of the culture of individuals who have generated this knowledge.
\end{abstract}

Keywords Cultural Turn; Political Geography; Sign; Meaning; Political Act
${ }^{*}$ Department of Political Geography, Faculty of Geography, Tehran University, Tehran, Iran

${ }^{1}$ Department of Political Geography, Faculty of Geography, Tehran University, Tehran, Iran

\section{*Correspondence}

Address: Floor 2, NO. 3, First deadlock East Farrokh Alley, Kamali Intersection, Imam Khomeini Street, Tehran, Iran. Postal Code:

1333973131

Phone: - Fax: -

smirahmadi@alumni.ut.ac.ir

\section{Article History}

Received: November 28, 2017

Accepted: October 01, 2018

ePublished: December 09, 2018

\section{I T A T I O N L I N K S}

[Agnew \& Muscarà; 2012] Making ...; [Atkinson, et al; 2016] Cultural geography: A critical ...; [Badiee Azandahi \& Mirahmadi; 2016] Emerging issues and ...; [Bell; 2009] Cultural studies and ...; [Blacksell; 2010] Political ...; [Boelens; 2014] Cultural politics and the hydrosocial ...; [Cox; 2005] Political geography: Critical ...; [Cox; 2014] Making human ...; [Dodds; 2011] Geopolitics: a very ...; [Fayyaz, et al; 2011] Semiotics of cultural landscapes in ...; [Fincher; 2004] From dualisms to ...; [Flint; 2011] An introduction ...; [Gallaher, et al; 2011] Key concepts in ...; [Gibson \& Waitt; 2009] Cultural ...; [Gregory, et al; 2009] The dictionary of ...; [Hubbard \& Kitchin; 2011] Thinkers on space ...; [Jazeel; 2013] The WileyBlackwell ...; [Jones, et al; 2007] An introduction to ...; [Jones; 2008] Categories, borders ...; [Kobayashi; 2009] Representation ...; [Laurie \& Calla; 2004] Development, postcolonialism ...; [Marston; 2004] Space, culture, state ...; [McEwan; 2003] Material geographies ...; [Minca; 2009] Postmodernism/ postmodern ...; [Mirheidar \& Mirahmadi; 2016] Evolution of ideas ...; [Newman; 2006] A companion to ...; [Ó Tuathail; 2000] The postmodern ...; [Paasi; 2009] Political ...; [Painter; 1995] Politics, geography ...; [Passi; 2003] Boundaries in ...; [Philo; 2009] Cultural ...; [Power \& Campbell; 2010] The state of critical ...; [Raghuram \& Madge; 2006] Towards a method ...; [Robinson; 2003] Political geography ...; [Scott; 2009] Representation ...; [Shakouie; 2003] New ideas in philosophy ...; [Sharp; 2004] Doing feminist political ...; [Sharp; 2006] Feminist and postcolonial ...; [Sidaway; 1997] Politics, geography and ...; [Smith; 2009] Humanism/Humanistic ...; [Staeheli \& Kofman; 2004] Mapping gender, making ...; [Toal \& Agnew; 2003] Political geographies ...; [Van Houtum; 2005] The geopolitics of borders ... 
Mirahmadi F. S. PhD

Ahmadi S. A. PhD

smirahmadi@alumni.ut.ac.ir

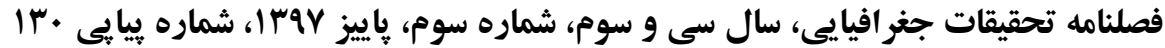

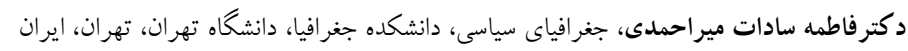

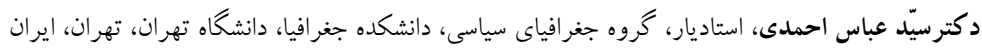

\section{جرخش فرهنكى در جغرافيا و تأثيرات آن بر رشتهُ جغر افياى سياسى}

يذيرش نهايى:MV/V/9

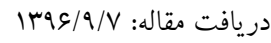

DOI: $10.29252 /$ geores.33.3.58

جكيده

مقدمه: جرخش فرهنكى مجموعهاى از تحولات فكرى است كه از اواخر دهه .191 حوزه صلاحيت رشته جغرافيا را

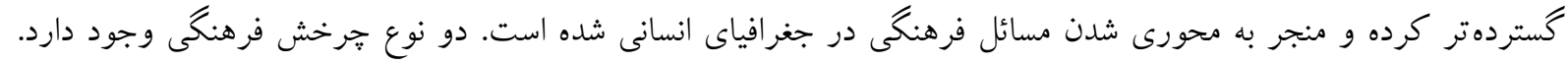

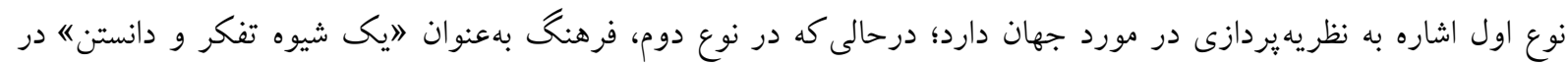
نظر كرفته مىشود.

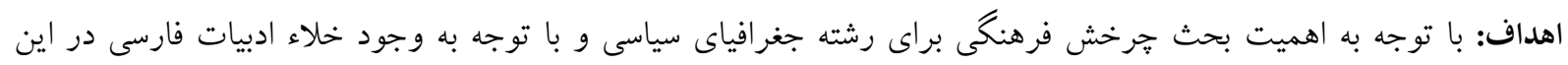

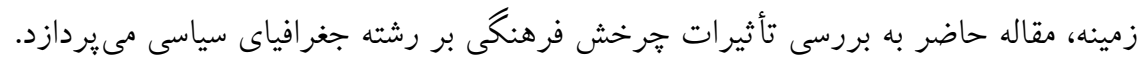

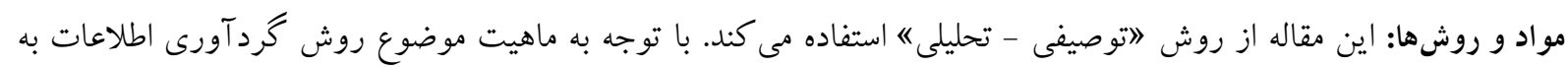

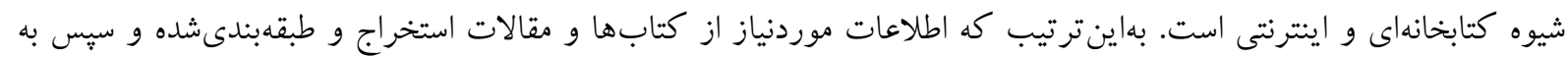

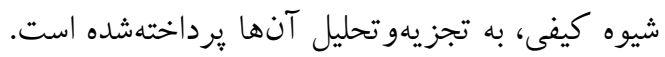

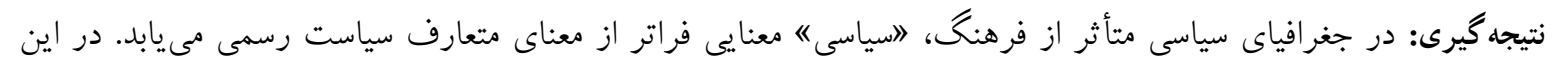

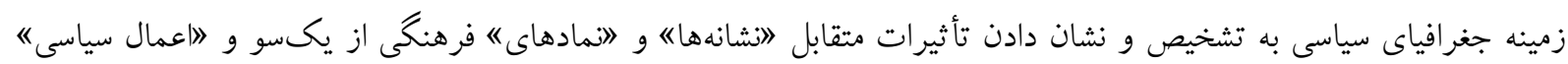

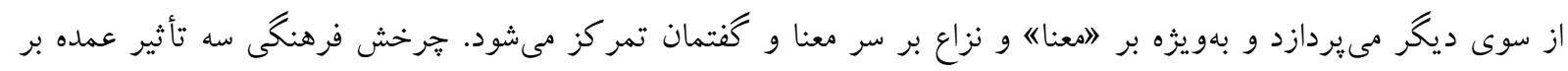

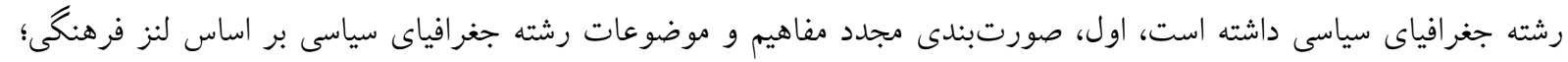

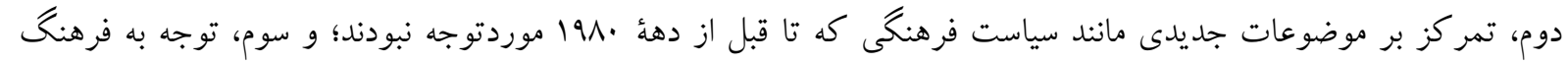

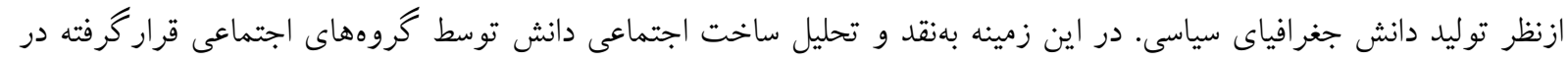

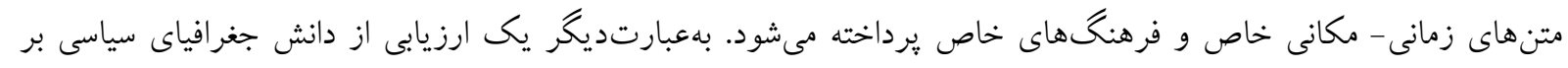

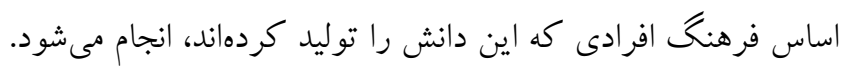

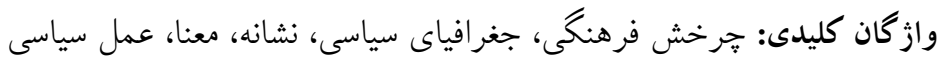

مقدمله

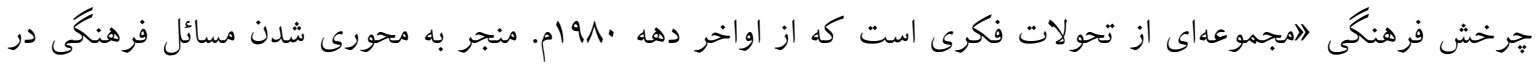

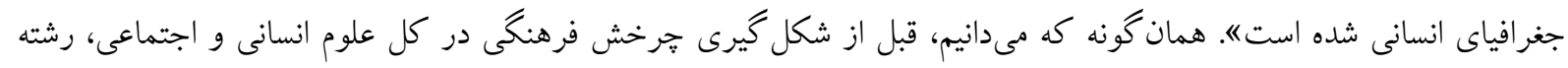

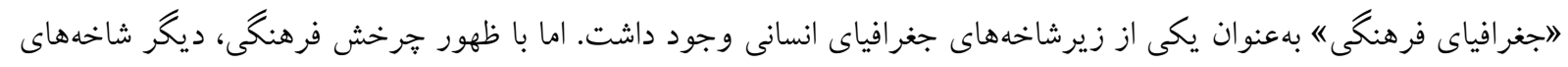


14. 14.

جغرافياى انسانى نيز بهنوبه خود فرهنكى شدند. البته، جرخش فرهنگى بر خود رشته جغرافياى فرهنكى نيز تأثير كذاشت و

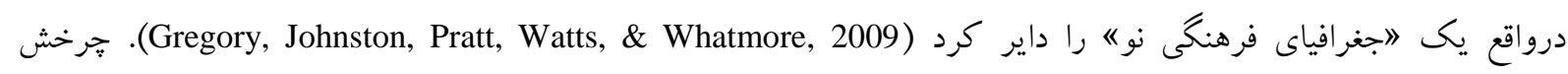

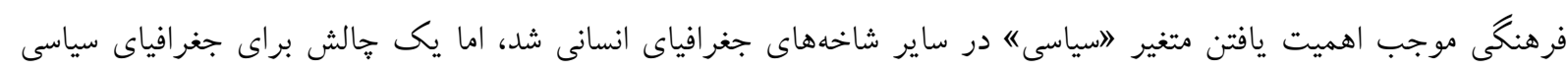
حكومتمحور بود؛ زيرا جفت شدن فرهنگ و حكومت در رشته جغرافياى سياسى غيرمعمول بود (Sidaway, 1997). باوجود اين كه برخى جغرافيدانان سياسى مانند بِينتر در دهه ·99 ام. فراخوانى براى تعامل سودمند رشته جغرافياى سياسى با توسعهاى

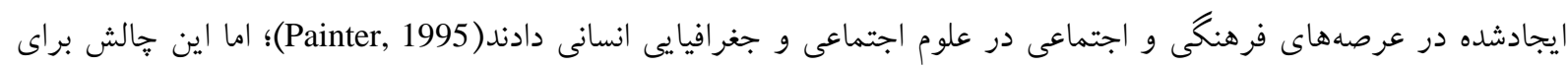
رشته جغرافياى سياسى باقى ماند و به نظر مىرسد كه همجنان موجود است. بدين معنا كه در رشته جغرافياى سياسى رويكردهاى حكومت كرا بهدوراز رويكردهاى فرهنخ گرا باقىماندهاند (Marston, 2004). هرجند در دهئ كذشته، در رشتهُ جغرافياى سياسى به مباحث فرهنگى توجه بيشترى شده است؛ بالينحال، به دليل ابهام در ماهيت جرخش فرهنگى (Bell, 2009)، همجنان

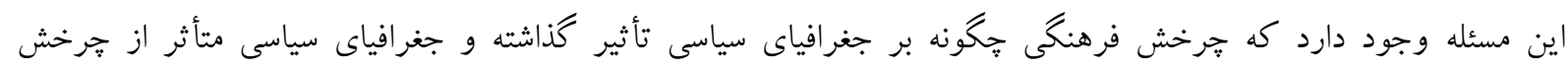

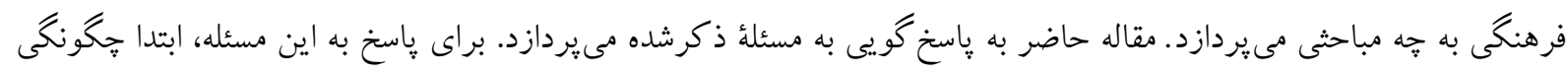

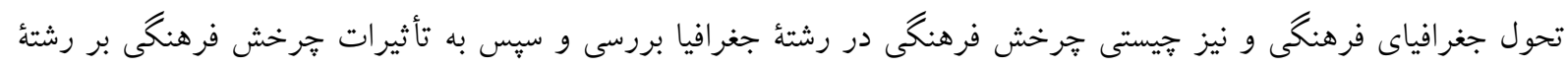
جغر افياى سياسى يرداخته مىشود.

روش تحقيق

اين يزوهش از نوع تحقيقات "بنيادى نظرى" است؛ روش تحقيق آن نيز "توصيفى - تحليلى" است. با توجه به ماهيت موضوع، روش كردآورى اطلاعات به شيوه كتابخانهاى و اينترنتى است. بهاينترتيب كه اطلاعات موردنياز از كتابها و مقالات استخراج و طبقهبندى شده و سيس به شيوه كيفى، به تجزيهو تحليل آنها يرداخته شده است. جارجوب نظرى ا إ. جغر افياى فرهنكى در طول بيشتر قرن بيستم، سه رويكرد عمده در جغرافياى فرهنكى وجود داشت. اول، در امريكاى شمالى، سنت غالب مكتب بر كلى بود كه بر اساس تحقيقات كارل ساور ساخته شد. ساور يك تمر كز جغرافيايى بر "جشمانداز" داشت كه بر كرفته از تحقيقات جغرافياى آلمانى در مورد لندشافت بود، دوم، در سنت فرانسوى توجه عميقى به ارتباط مردم و مكانها ازنظر

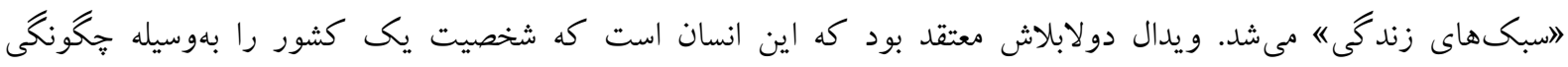

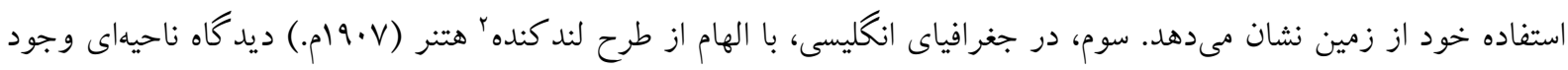
داشت كه به زيربناى طبيعى و روبناى اجتماعى توجه داشت؛ بهاينترتيب كه از زمينشناسى شروع مى كرد و سيس سيس به

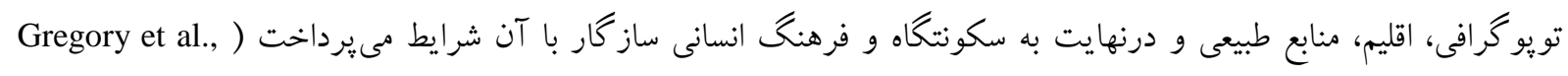

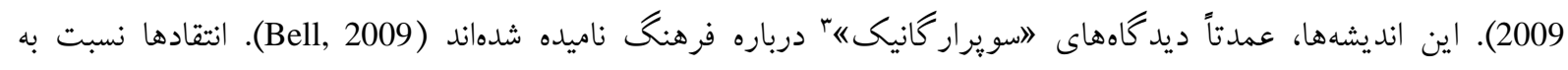
كرايش هاى سويرار گانيك در مورد فرهنخ، طى ها سال آخر قرن بيستم به وجود آمد. ابتدا جغرافيدانان انسان كرا كه بر مطالعهُ ادراك، ارزش و معانى و بر اهميت كاركزار انسانى تأكيد داشتند (Cox, 2005)، يك تصوير از انسان بهعنوان عاملى كه تعمداً بر اساس دلايلى در يرتو نيتها، منافع، و ارزشها عمل مى كند را توسعه دادند (Smith, 2009)؛ و عدم دغدغهُ جغرافياى فرهنكى براى توجه به "فرد" و تفاسير و اعمال فردى را به جالش كشيدند. دوم، جغرافيدانان راديكال، فمينيست و مار كسيست

1 Landschaft 
فرضيات تماميت گراى ار كانيكى نسبت به فرهنگ را موردنقد قراردادند؛ و به تمايزات داخلى، تضادها و مناقشات اشاره كردند.

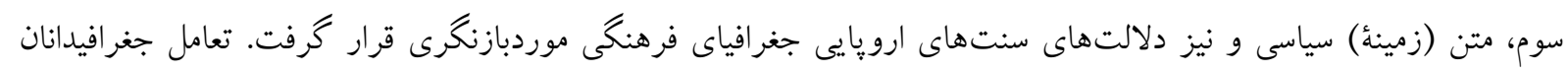

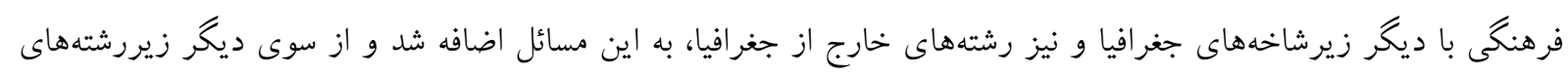

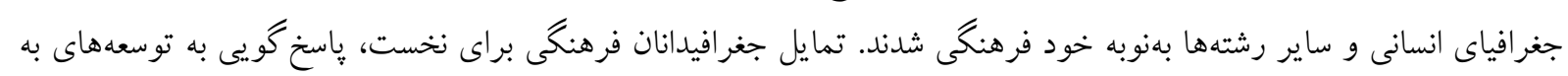

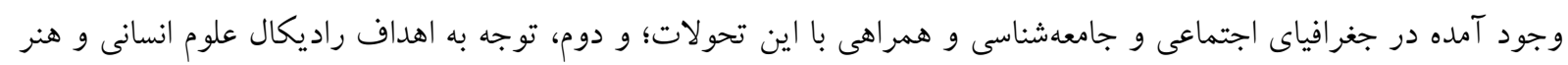

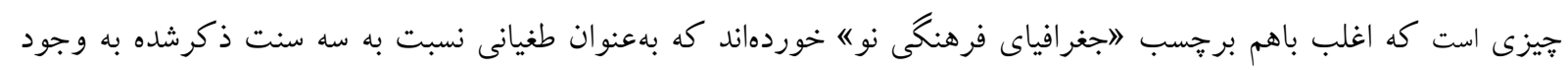

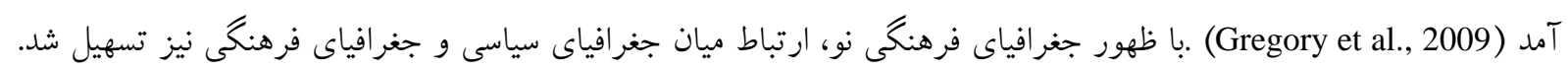

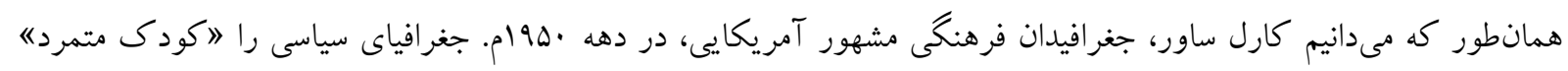

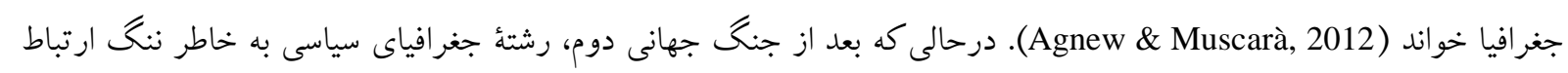

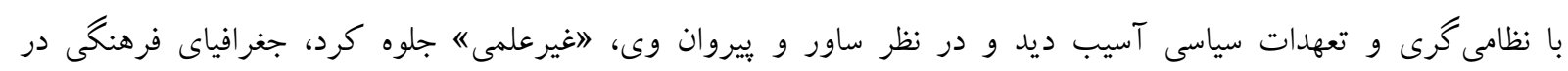

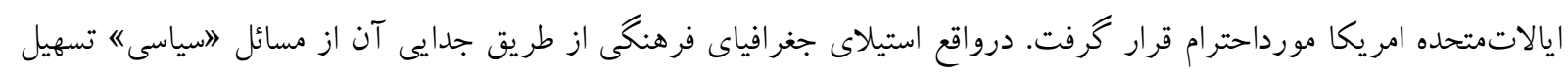

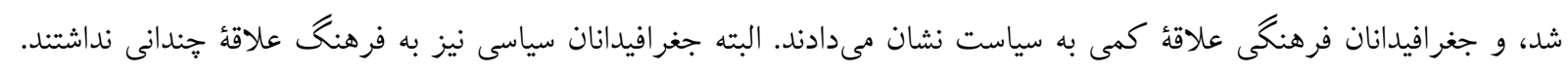

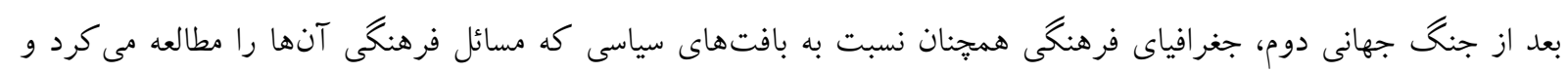

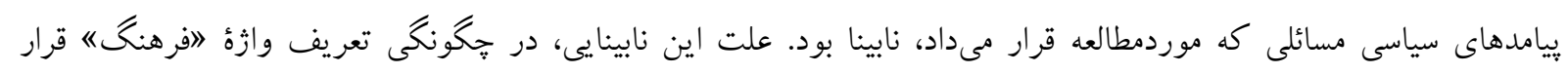

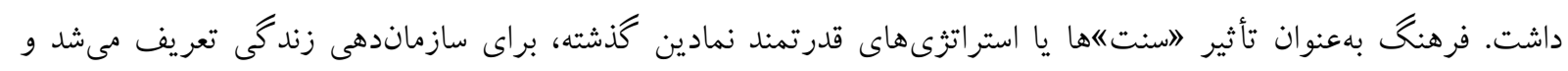

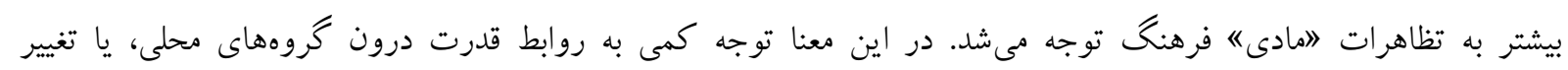

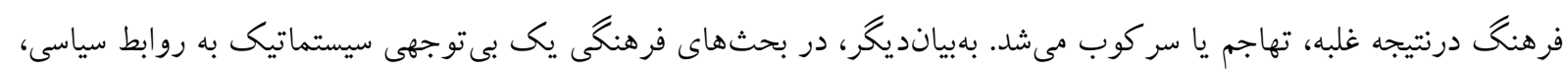

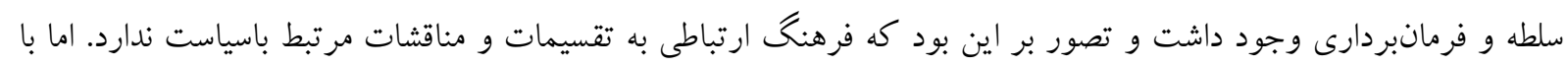

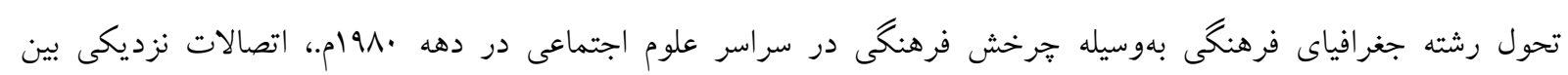

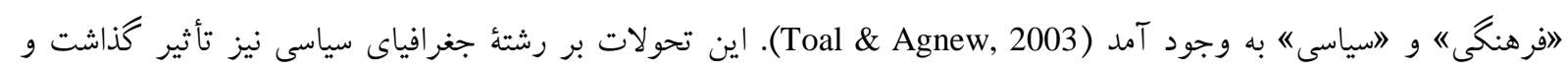

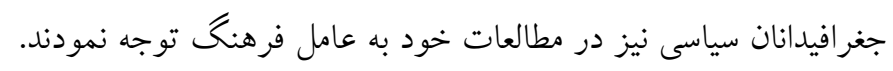

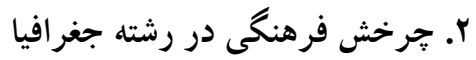

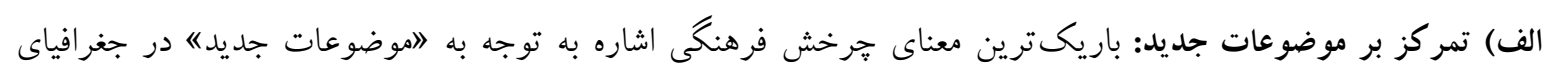

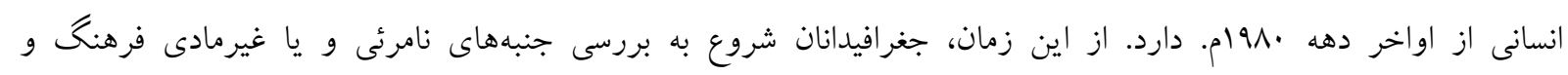

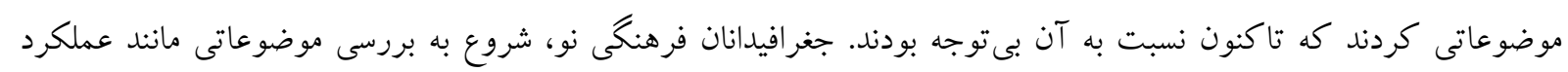

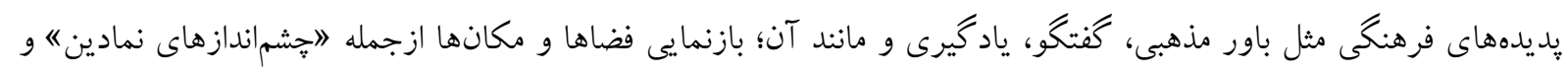

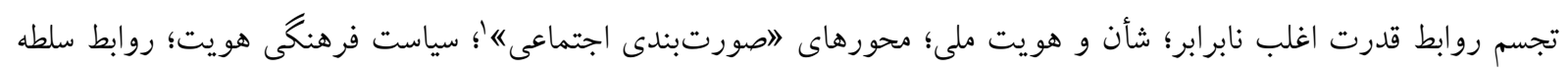

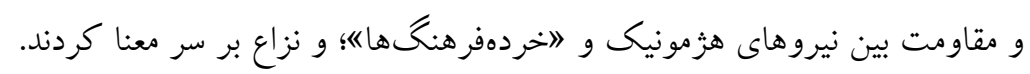

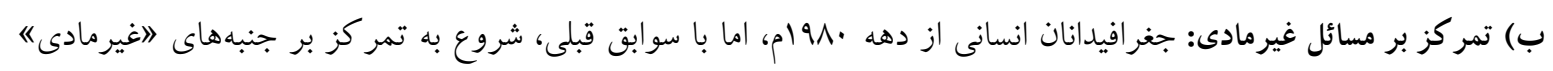

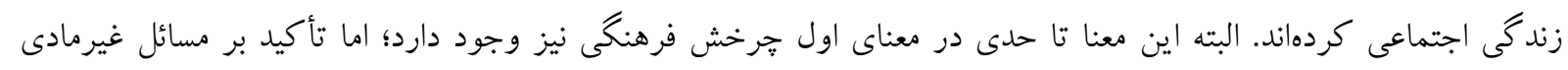

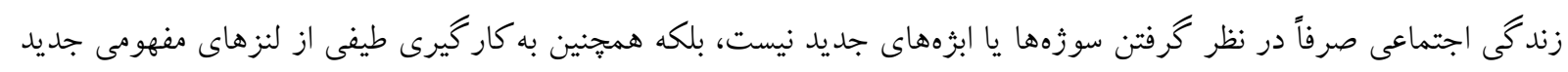

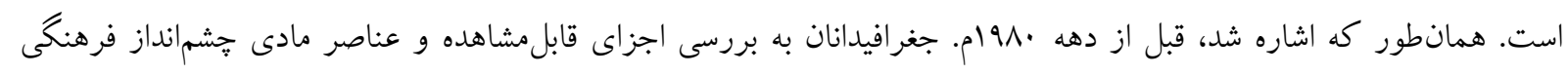




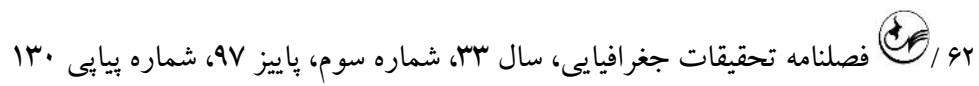
تمايل داشتند. جغرافيدانان انسانگرا، به عناصر غيرمادى و به مسائلى مانند ادراك انسان، تفسير، معانى و ارزشها توجه كردند و بهجاى امور مادى، بررسى امور ايدهآل را اولويت قراردادند (Philo, 2009)

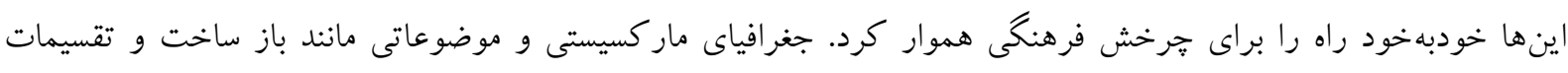

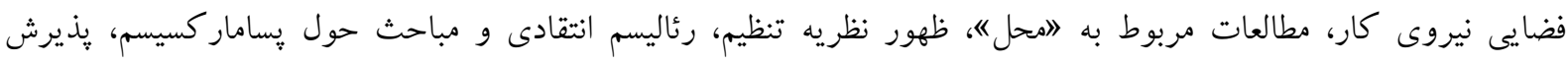

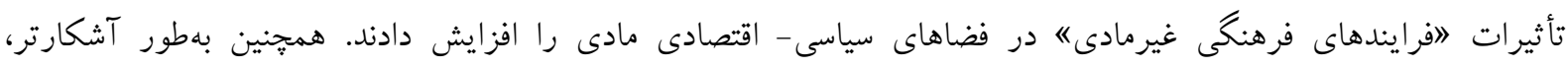

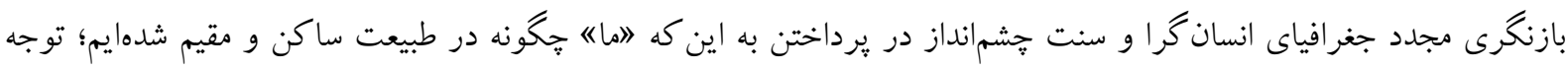

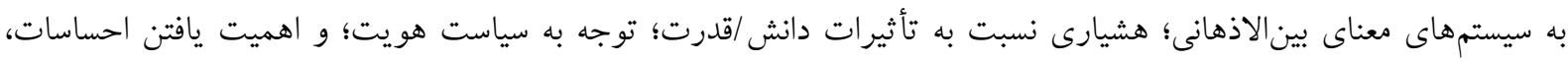

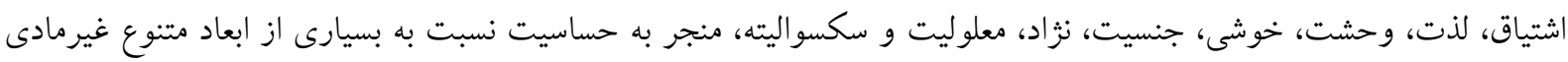

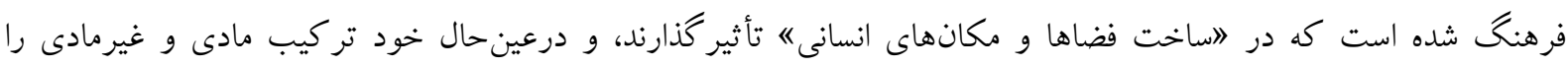

تشديد مى كنند (Philo, 2009).

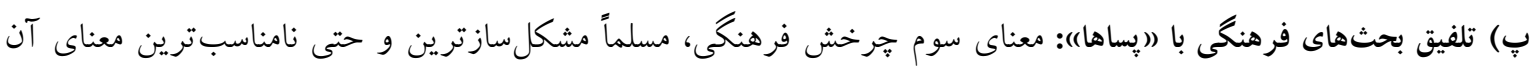

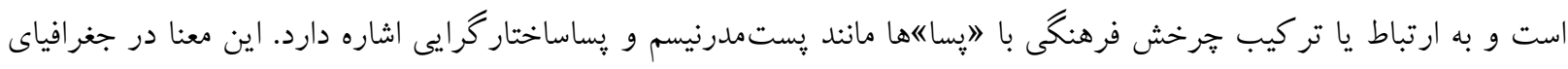

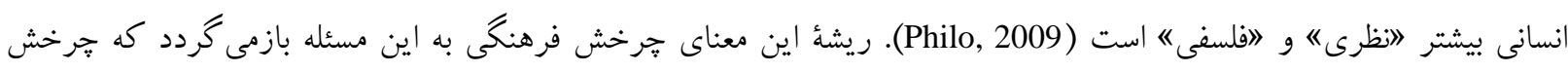

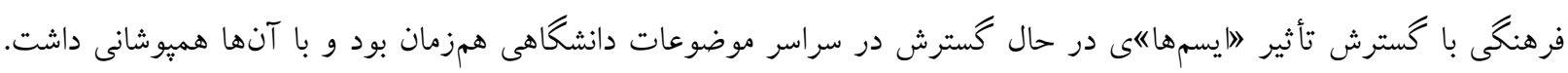

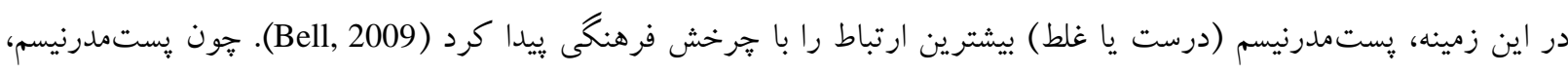

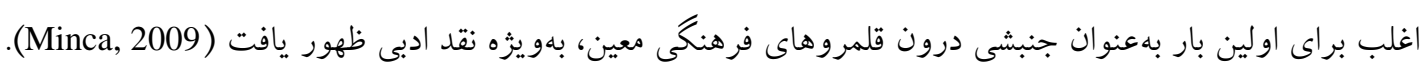

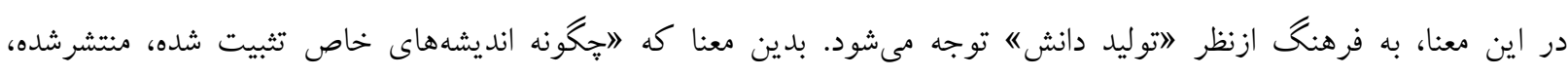

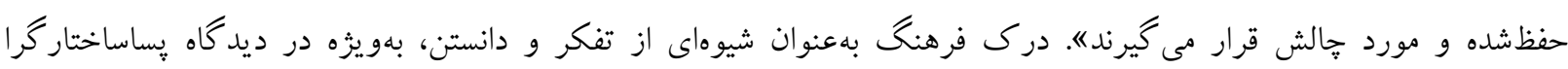

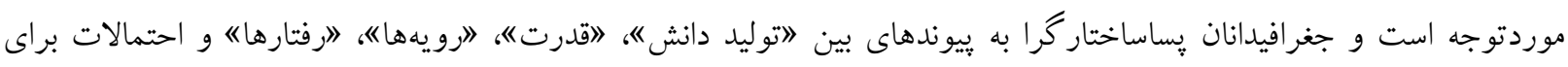

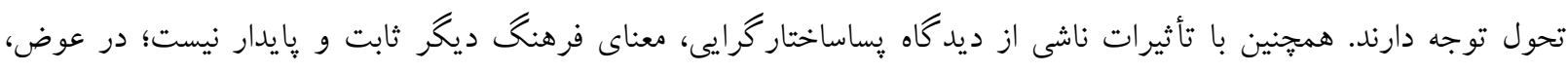

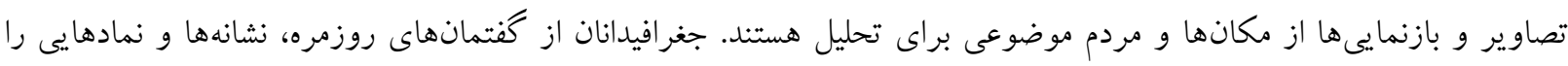

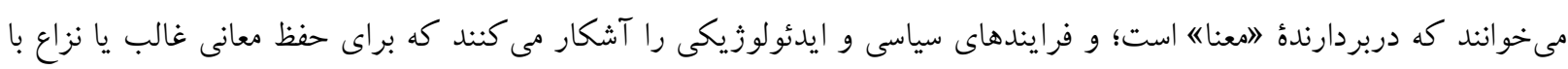

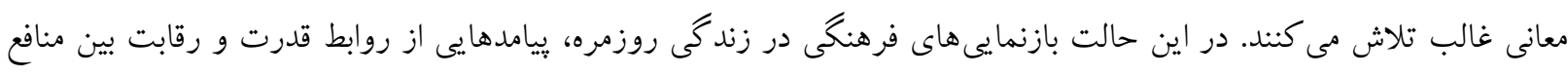

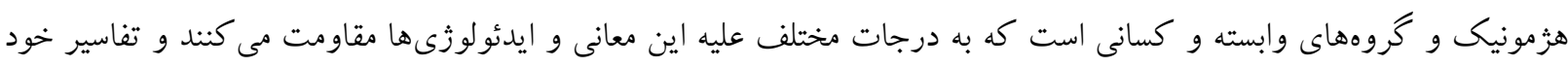

را بيان مى كنند (Gibson \& Waitt, 2009).

بنابراين، دو نوع جرخش فرهنكى وجود دارد. اولى اشاره به نظريه يردازى در مورد جهان دارد؛ درحالى كه دومى فلسفىتر و

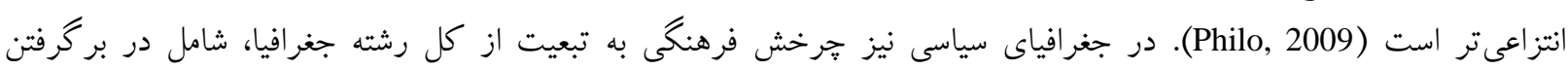

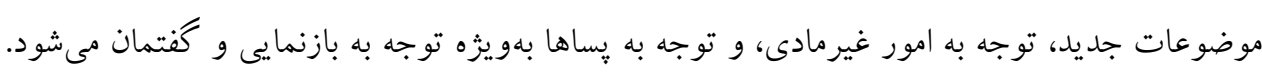

يافته هاى تحقيق

قبل از ورود به بحث تأثيرات خرخش فرهنكى بر رشته جغرافياى سياسى، لازم است يادآورى شود كه بنمايه و متغير

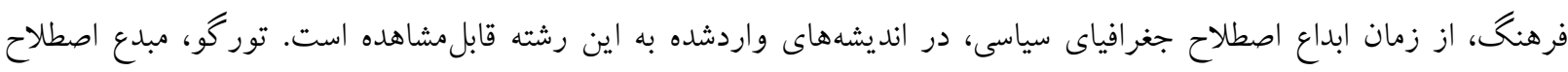

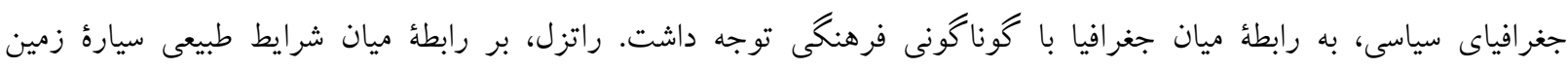

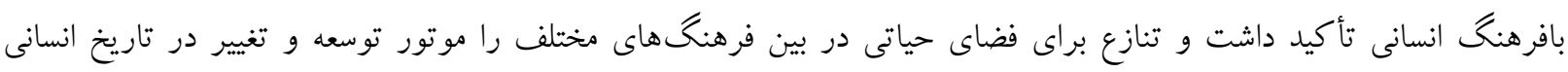


مىدانست. شلين نيز معتقد بود كه هرجه فرهنگ نيرومندتر باشد، براى گسترش سلطه يا كنترل بر سرزمينهاى بيشتر شايستهتر

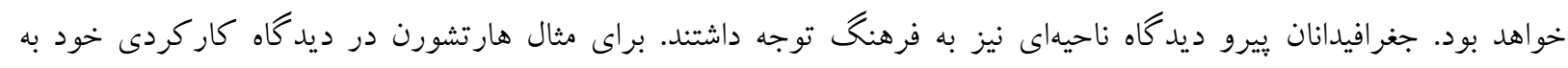

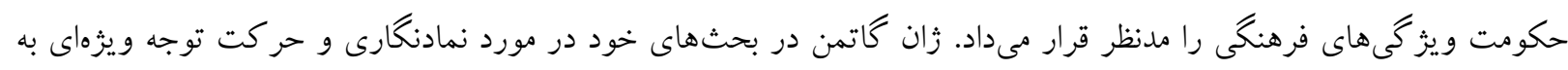

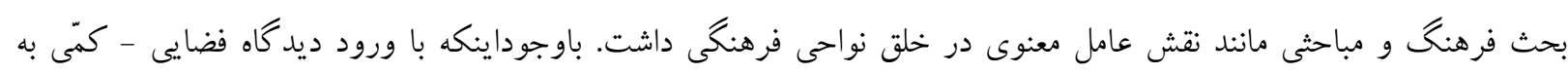

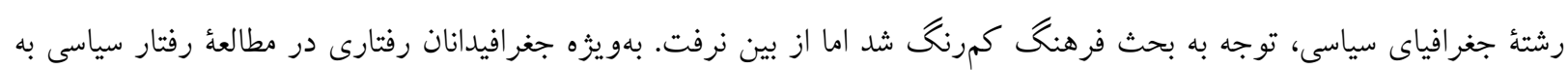

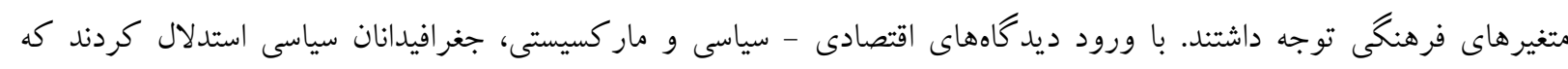

موضوعات فرهنگى را بايد درون يكى هار هوب مار كسيسى مطالعه نمود (Mirheidar \& Mirahmadi, 2016).

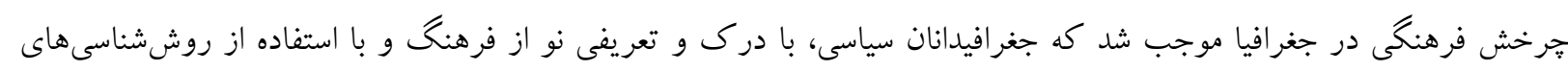

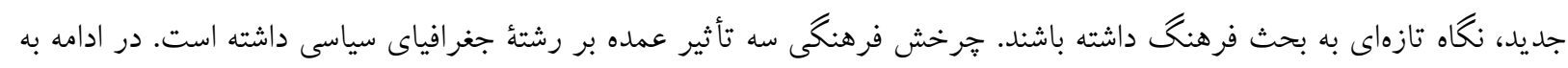
اين سه مورد برداخته مىشود:

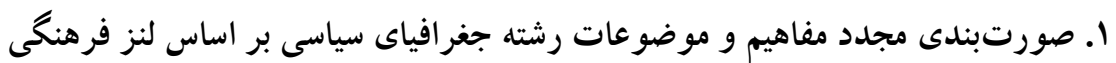

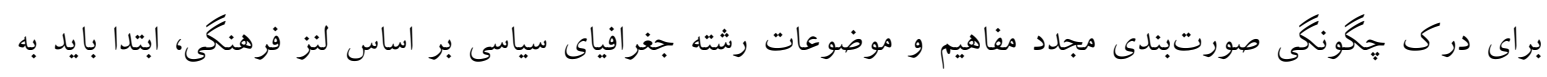

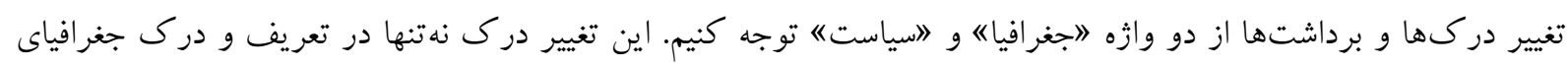

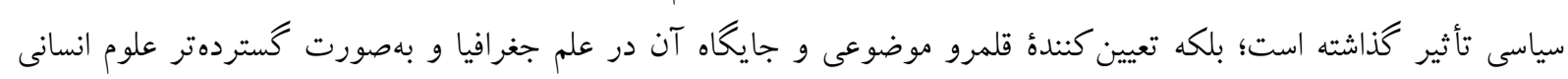

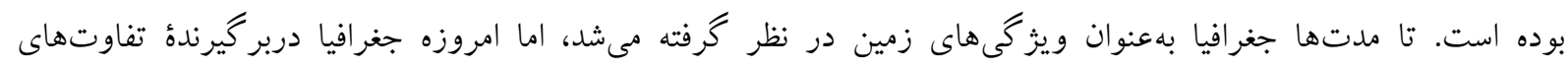

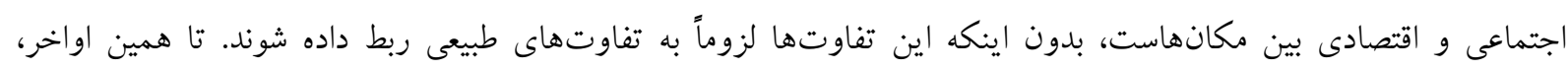

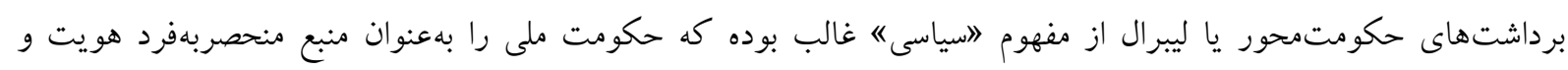

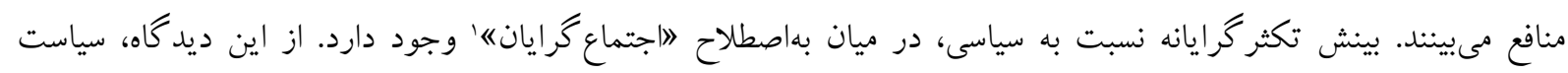

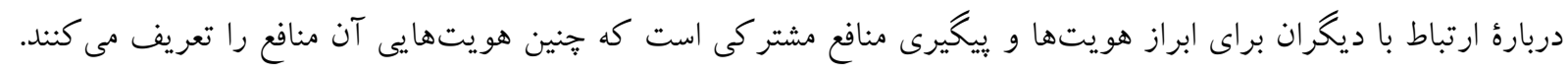

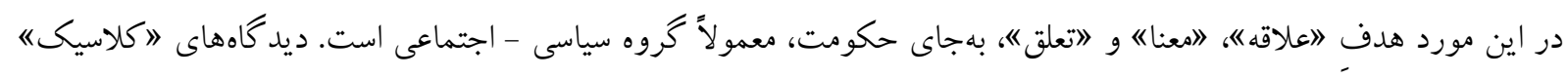

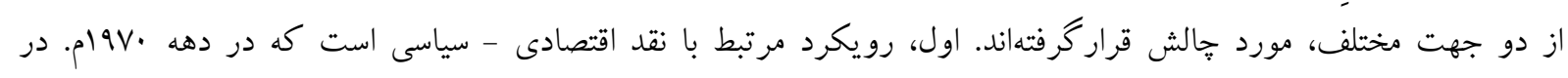

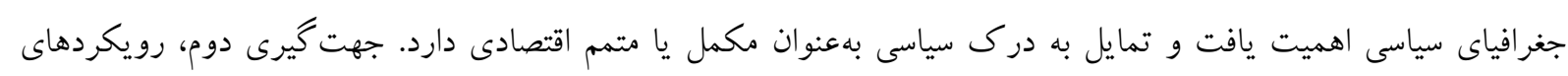

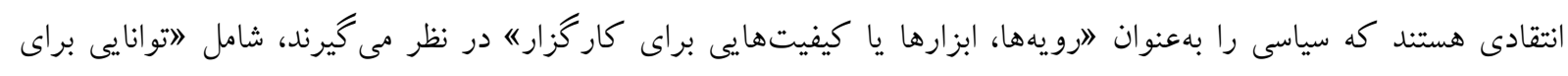

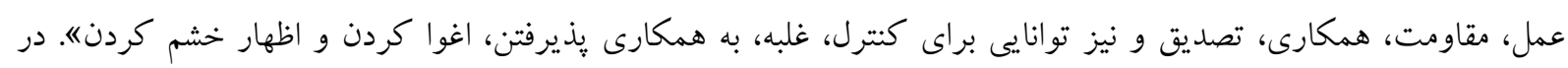

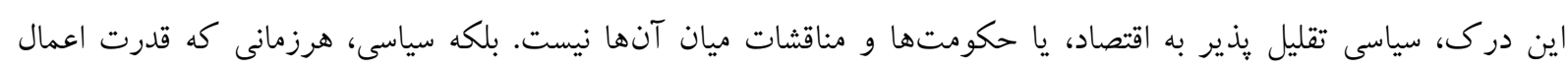

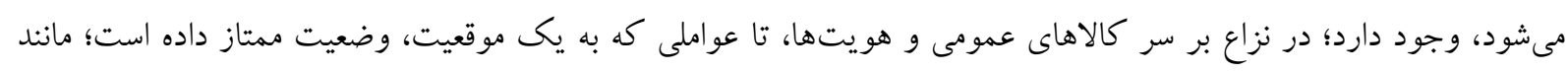

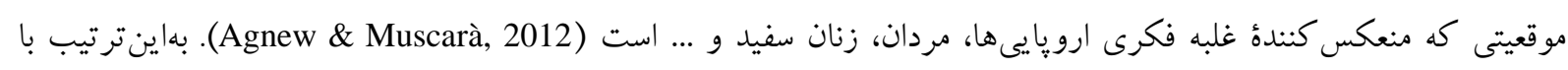

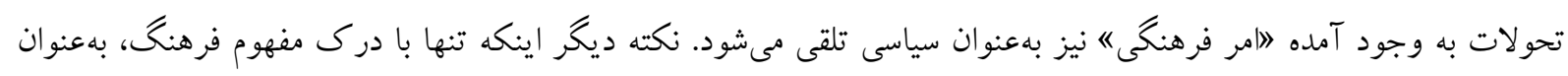

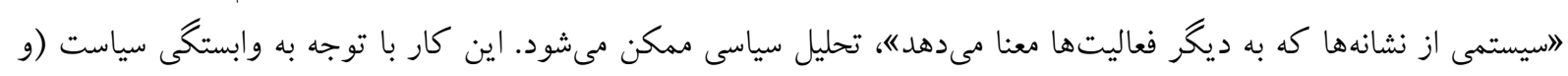

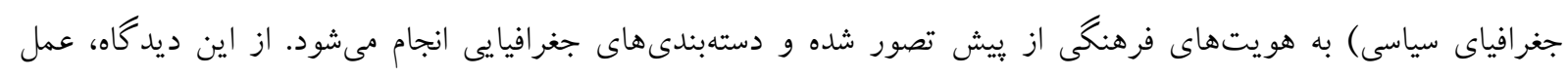

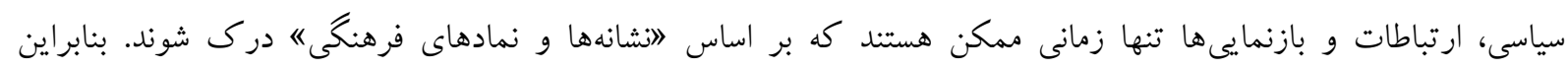

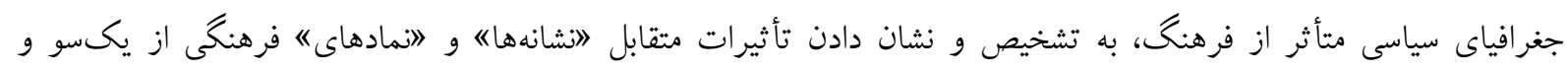




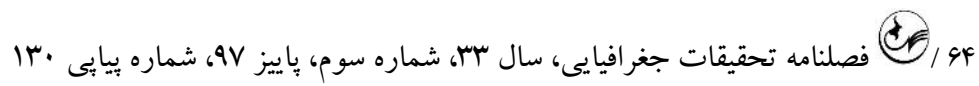

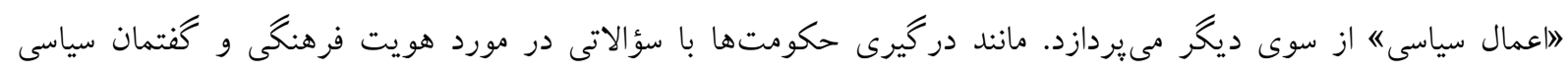
Sidaway, ) (Toal \& Agnew, 2003)

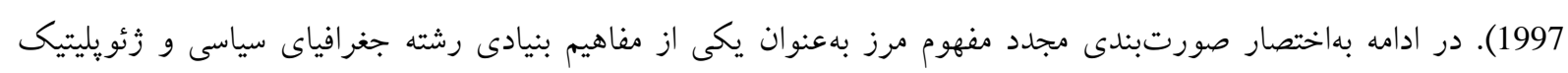

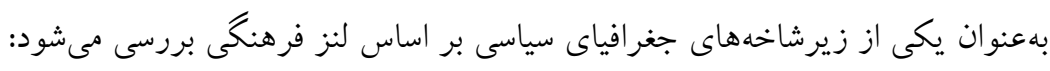

مرز

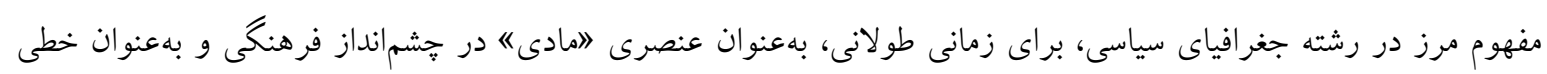

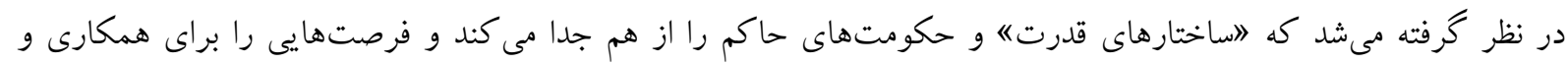

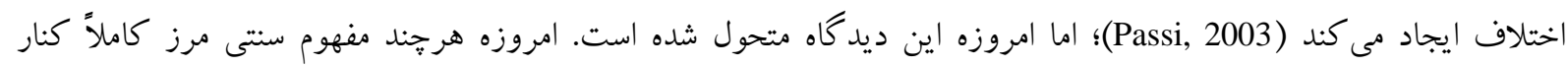

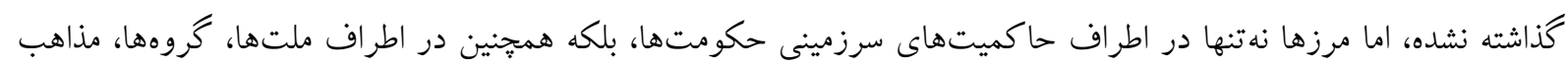

و نيز افراد كشيده مىشوند (Badiee Azandahi \& Mirahmadi, 2016).

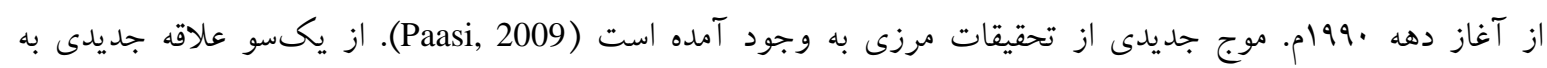

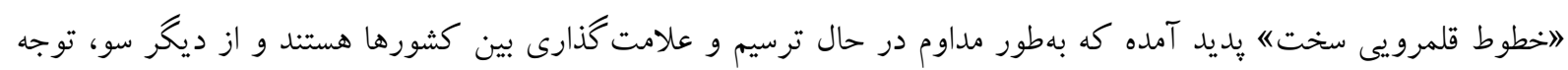

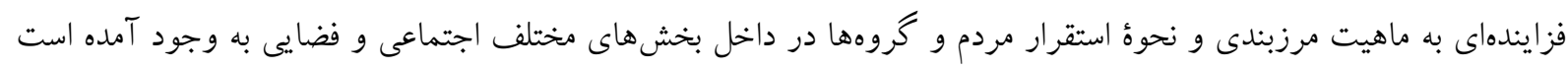
(Newman, 2006)

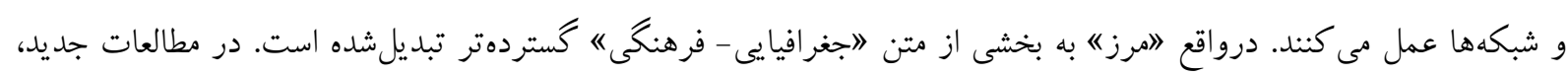

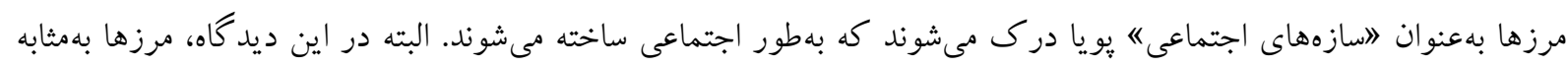

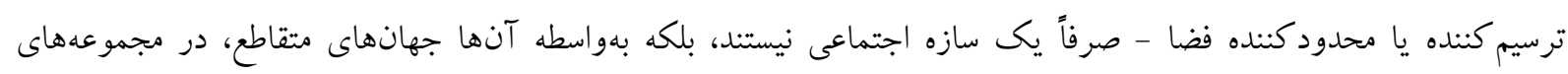

بى شمار و روش هاى متداخل قرار مى گيرند (Badiee Azandahi \& Mirahmadi, 2016).

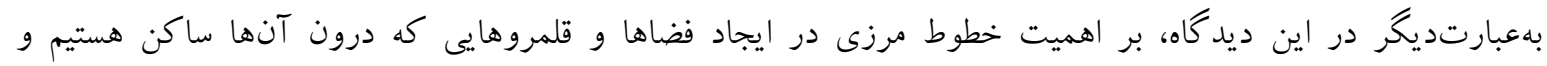

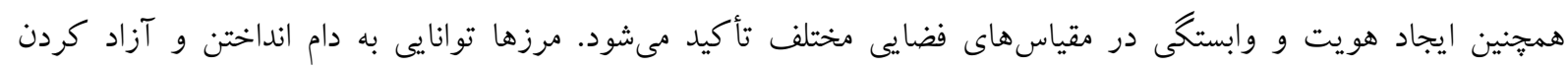

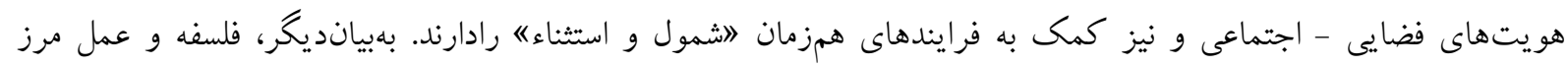

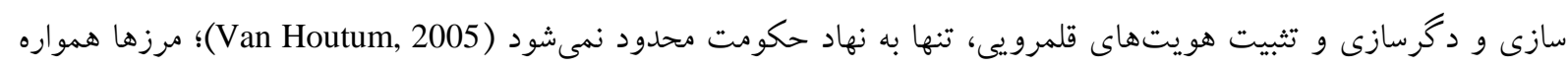

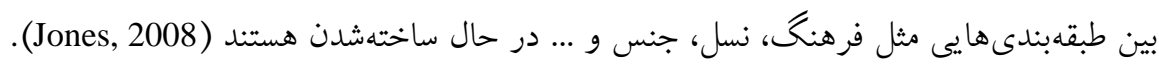

\section{زئو پيليتيك}

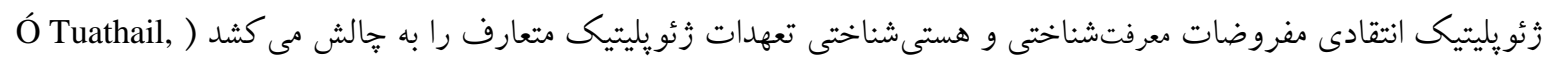

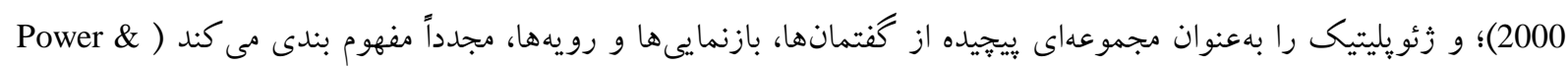

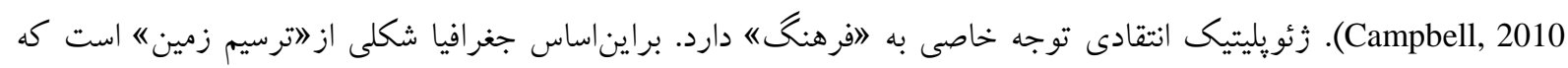

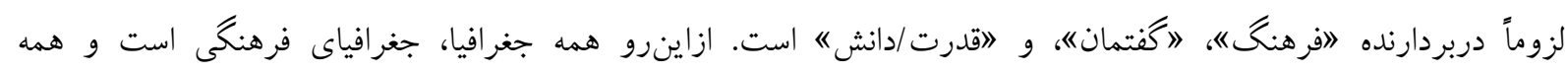

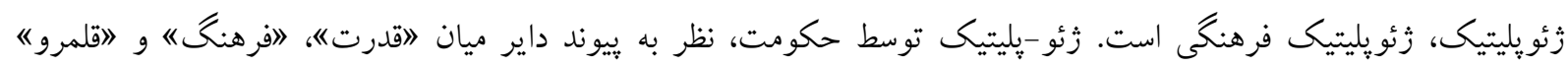

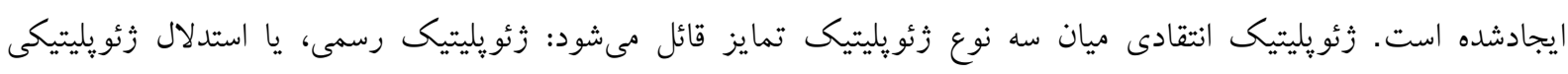

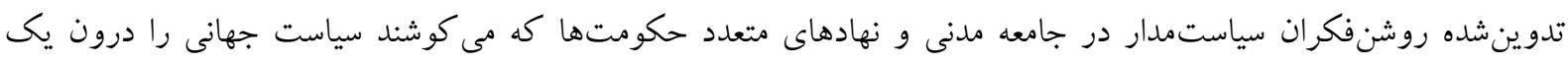

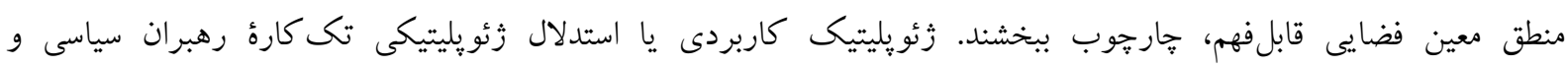

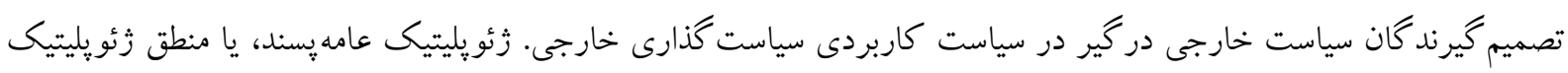


هويت و تفاوت كه در مظاهر گوناگون "افرهنگ عمومى" از رسانهاى بصرى گرفته تا مجله هاى خبرى و رمانها نفوذ مى كند (Atkinson, Jackson, Sibley, \& Washbourne, 2016)

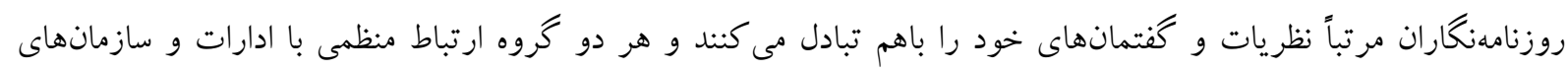

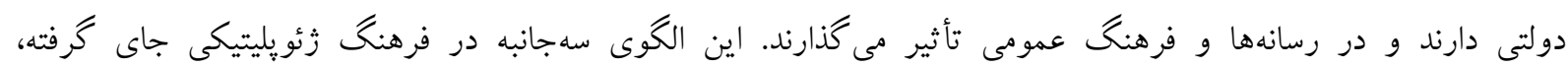

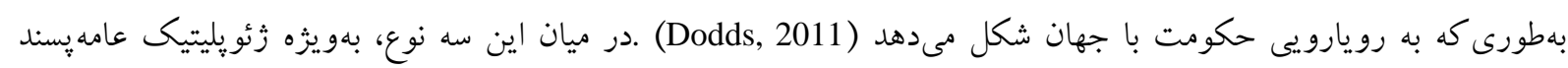

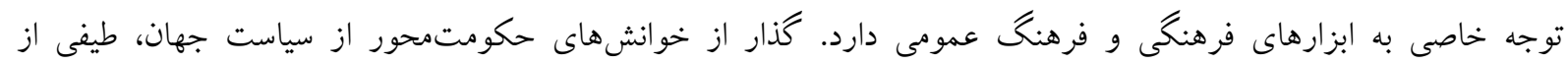

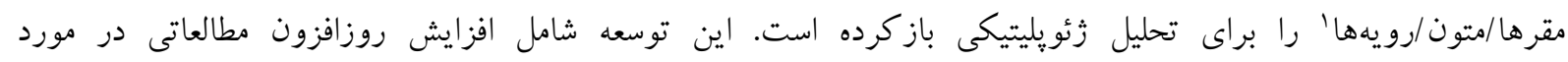

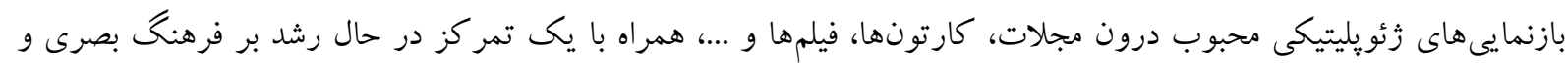

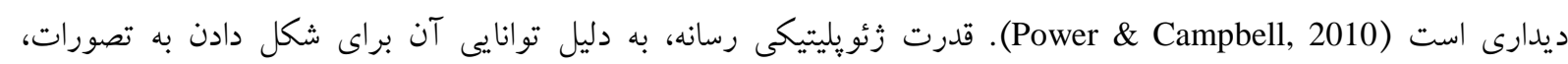

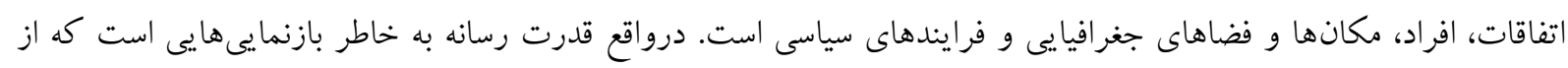

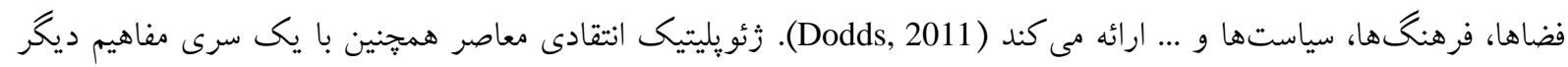

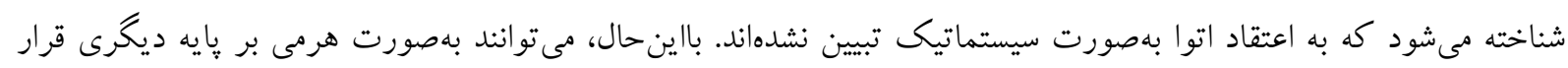

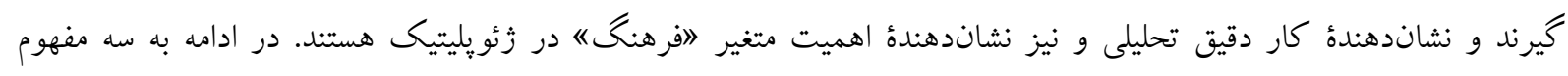

$$
\text { اشاره مىشود: }
$$

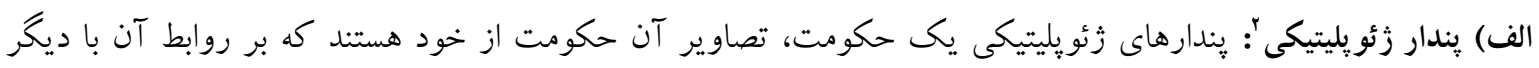

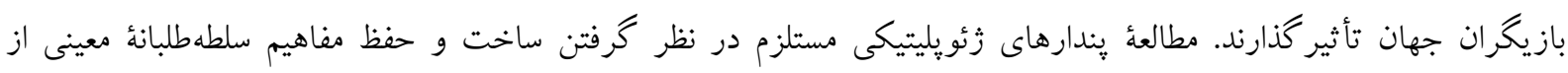

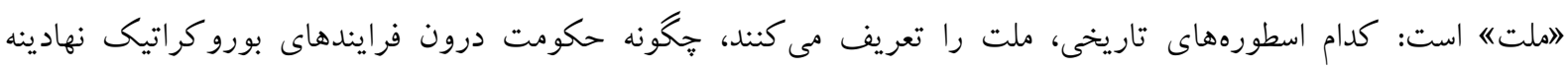

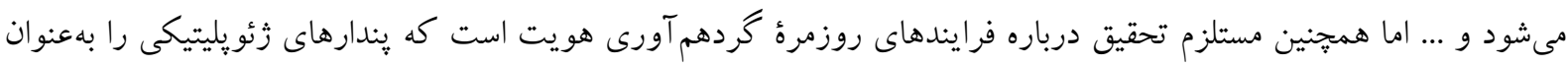

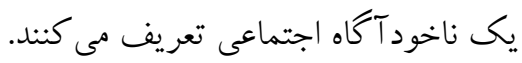

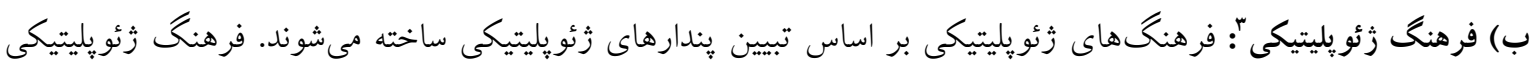

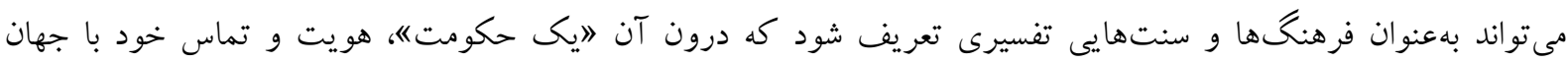

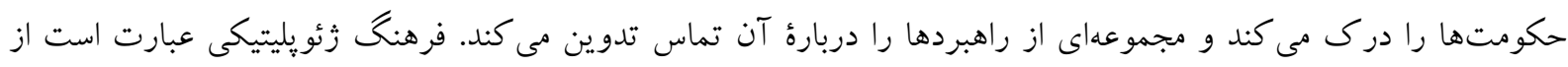

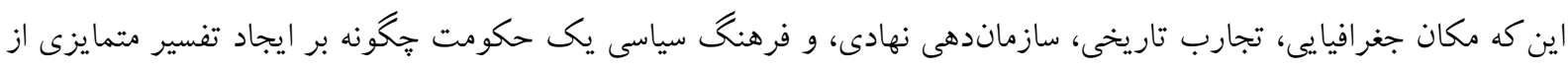

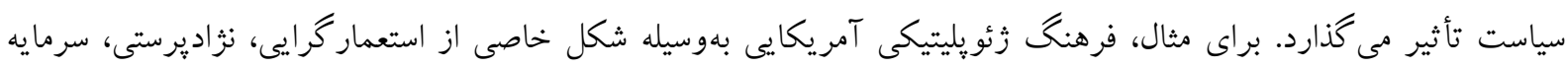

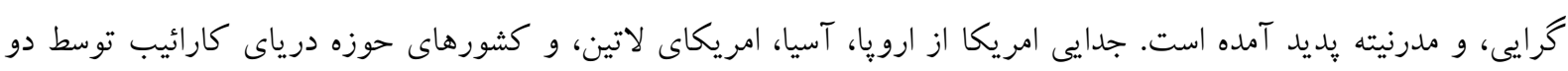

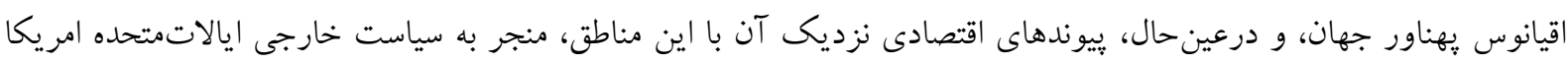

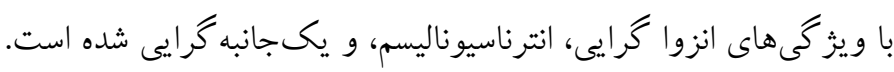

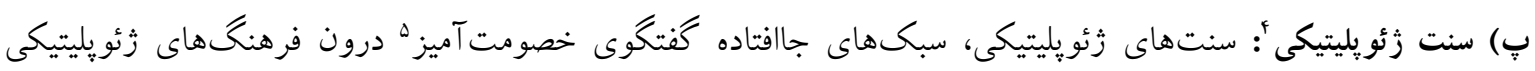

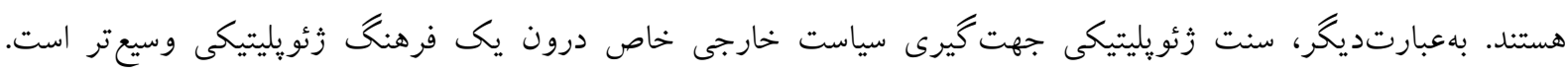

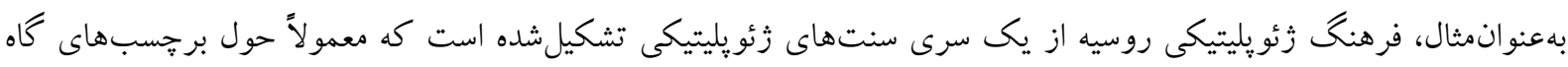

1 Sites/Texts/Practices

2 Geopolitical Imagi-Nation

3 Geopolitical Culture

4 A Geopolitical Tradition

5 Antagonistic Dialogue 


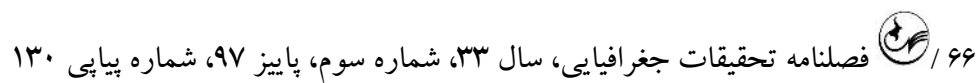
نايخته اغربى كردنه و \ارواسيايى شدنه تدوين شدهاند (Atkinson et al., 2016). اين سه مفهوم نشاندهندة اين واقعيت است

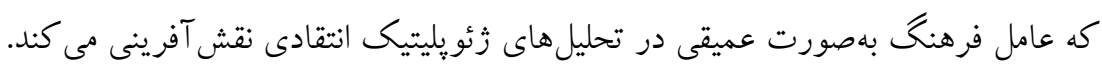
r. توجه به موضوعات جديد

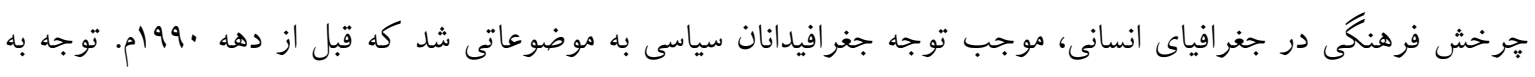

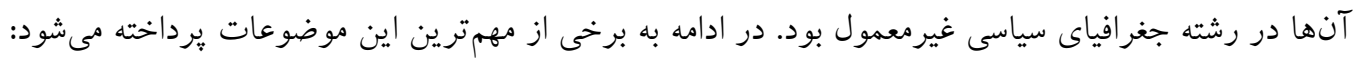

\section{هويت}

مهمترين تأثير ترخش فرهنكى بر جغرافياى سياسى، توجه به بحث الهويته است. دليل توجه به بحث هويت به اين

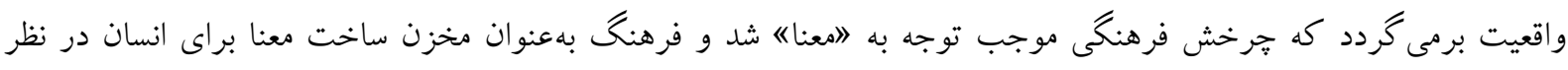

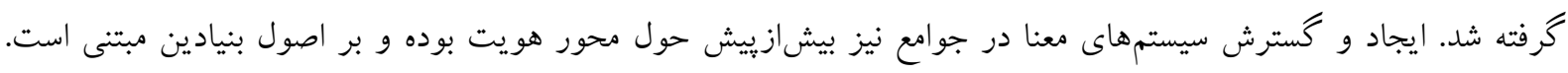
اين هويتها مى توانند هويتهاى ملى، سرزمينى، منطقهاى، قومى، مذهبى و شخصى باشند ( (Mountz, \& Shirlow, 2011

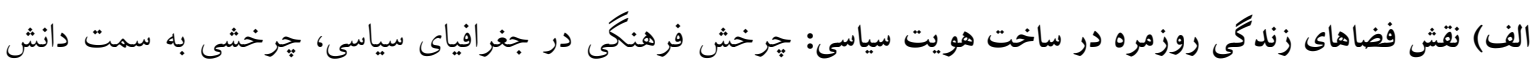

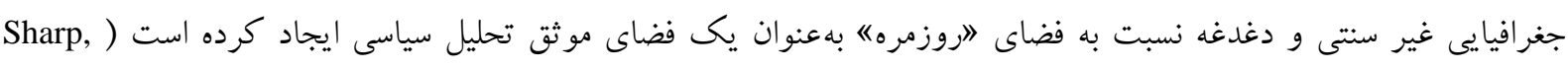

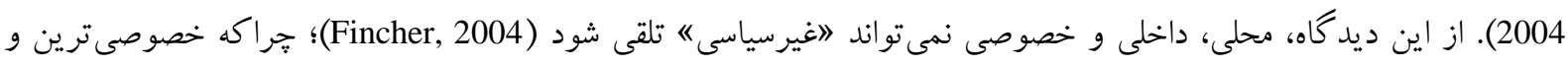

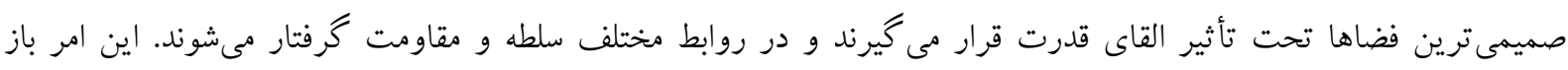

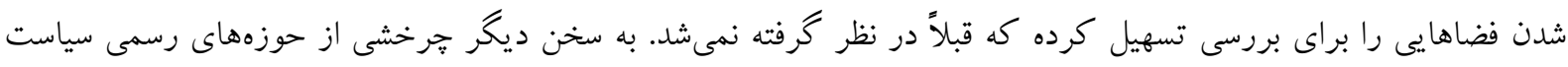

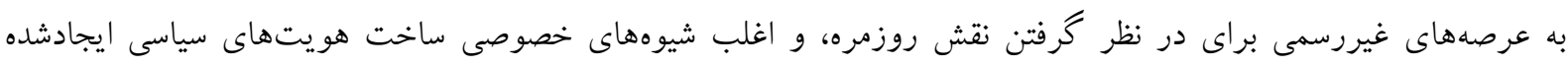

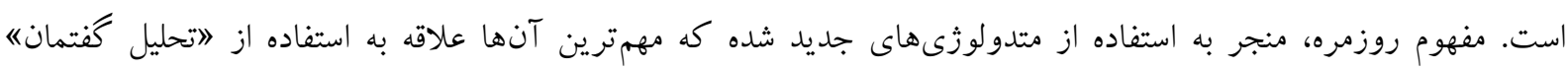

جهت تحليل ساخت هويتهاى سياسى بوده است (Sharp, 2004).

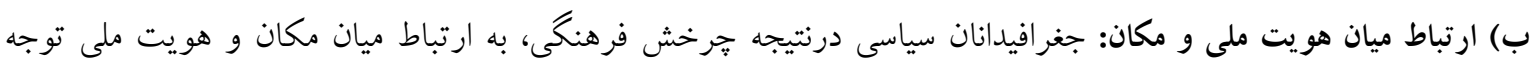

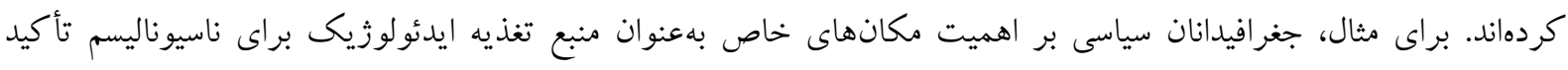

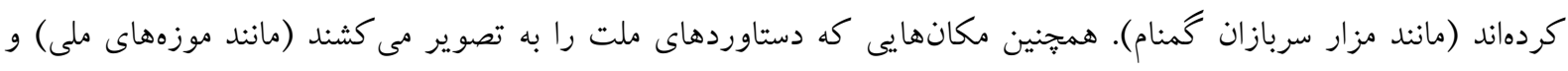

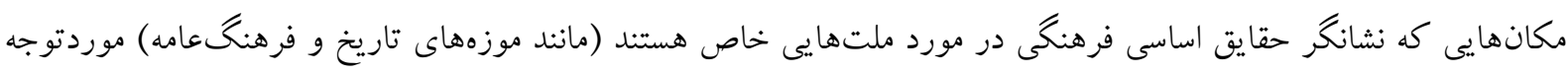
جغرافيدانان سياسى هستند (Jones, Jones, \& Woods, 2007).

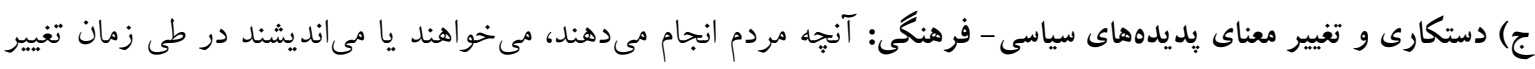

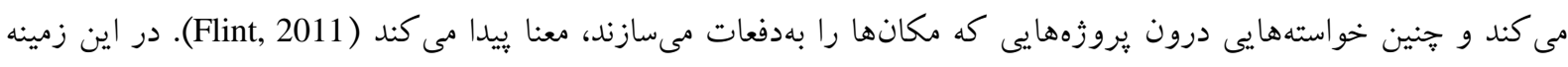

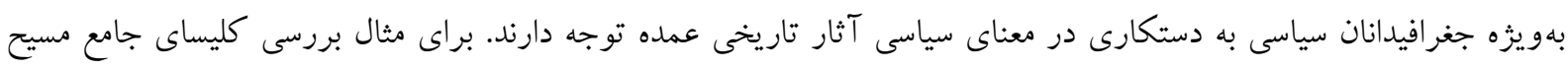

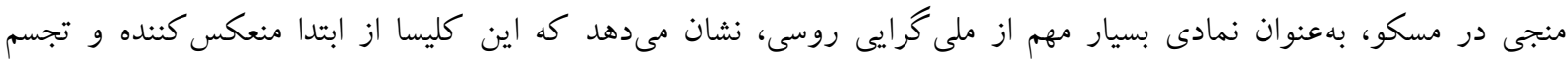

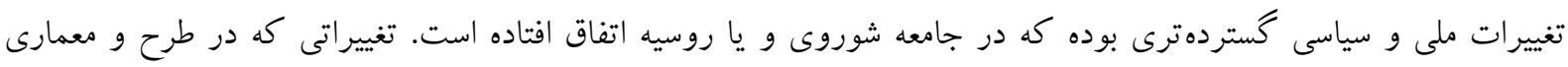

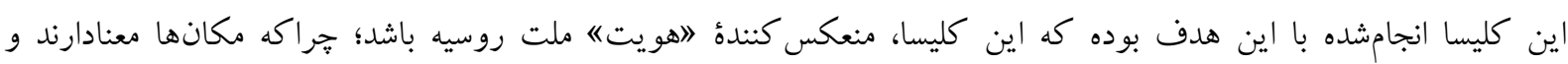

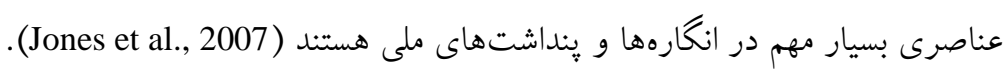

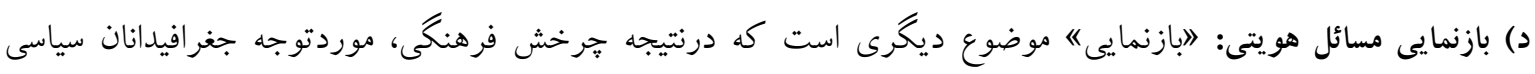

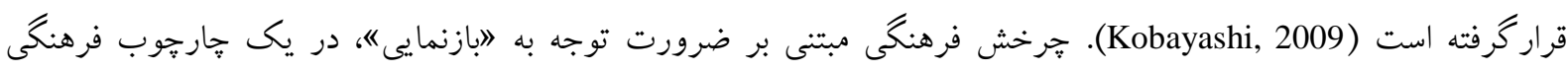


است. اين توجه باهدف شناخت بيشتر نحوه تأثير تصوير، زبان و تبادل انديشه بر شكل گيرى 》واقعيته است. بازنمايى ابزارى

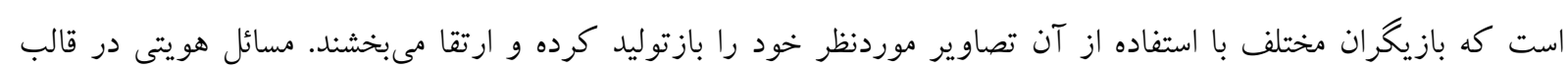

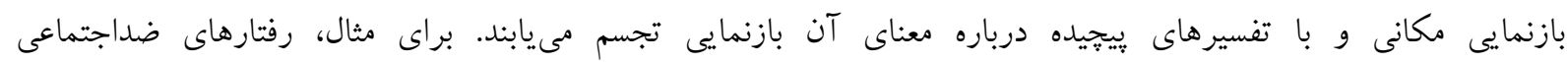

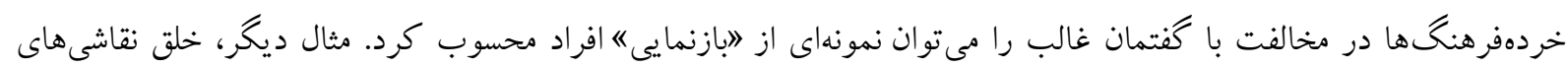
ديوارى غيررسمى، بهعنوان اقدامى براى طرح دعواى مالكيت بر يك مكان است (Gallaher et al., 2011).

\section{جشمانداز}

جشمانداز، يك مبحث ديريا در رشتهُ جغرافياست. اما همانطور كه بيان شد، دركذشته جغرافيدانان به واقعيتهاى عينى و

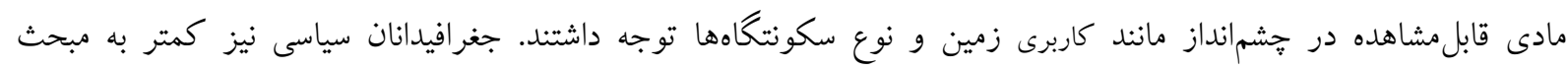

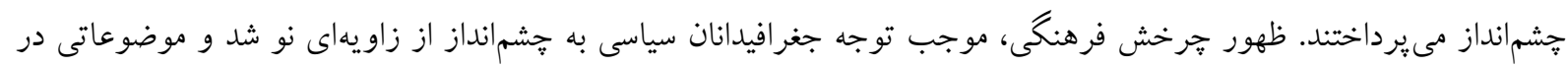

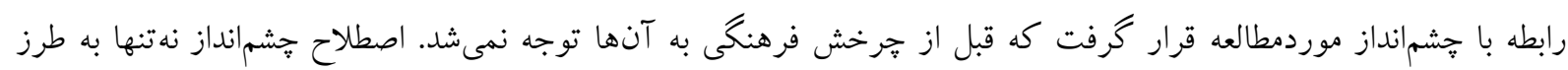

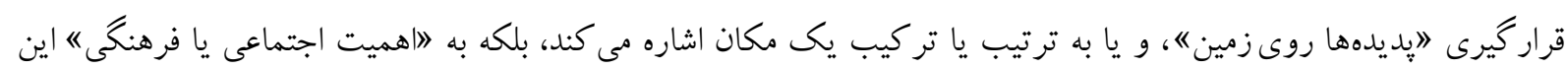

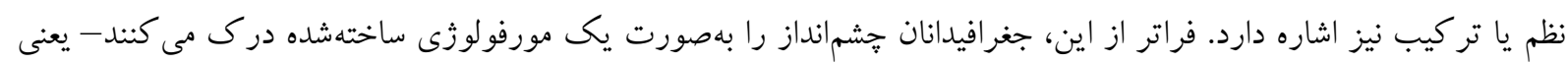

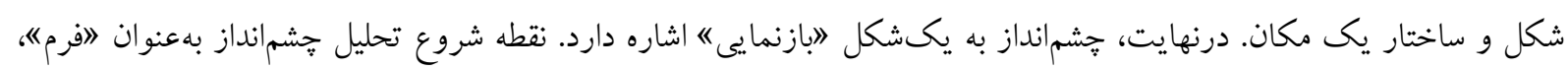

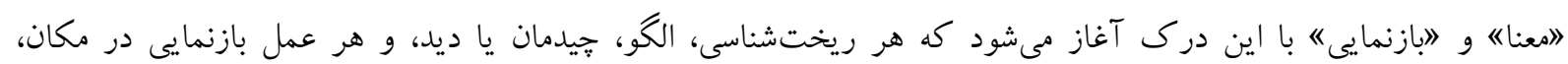

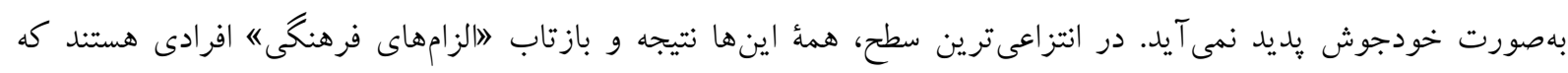

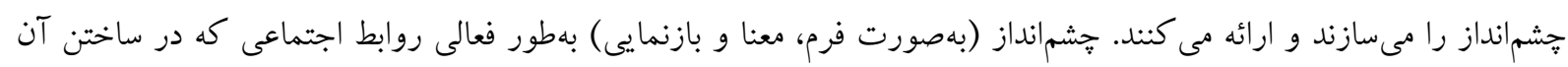

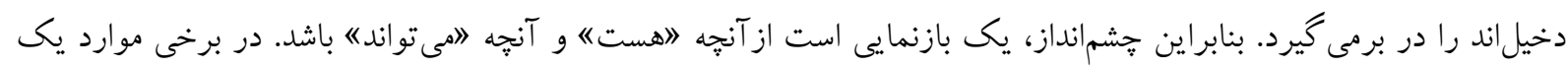

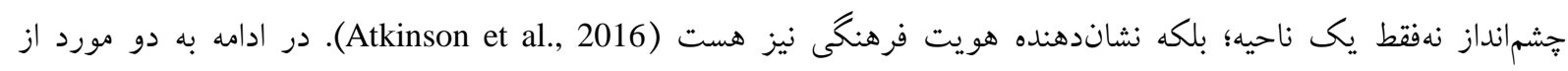
مهم ترين موضوعات موردتوجه جغرافيدانان سياسى برداخته مى شود:

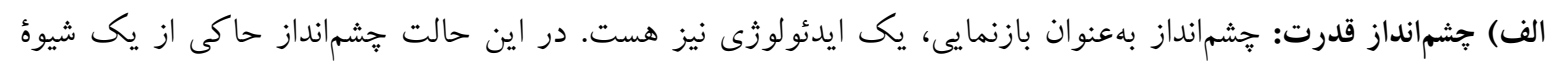

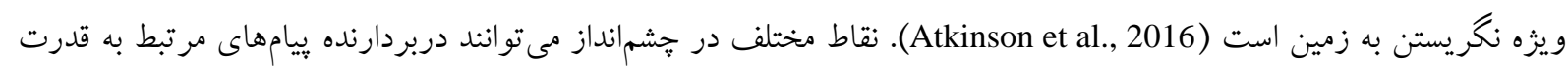

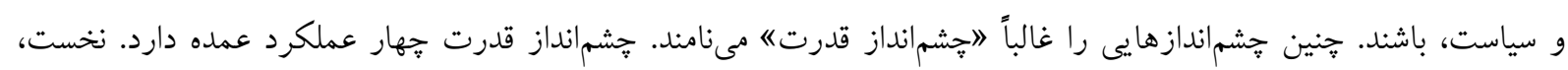

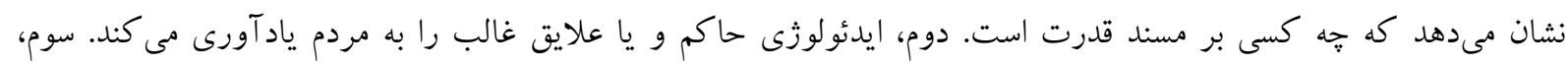

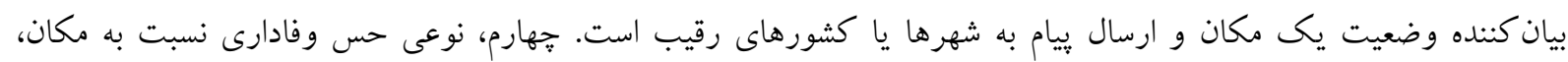

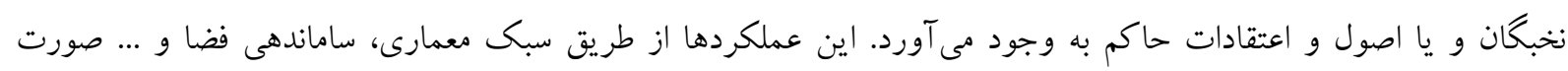
مى گيرند (Jones et al., 2007).

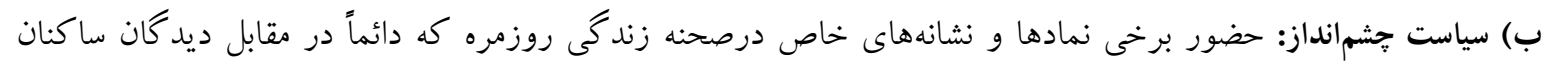

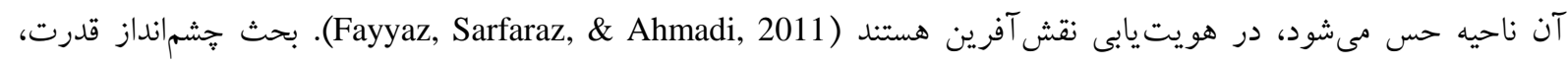

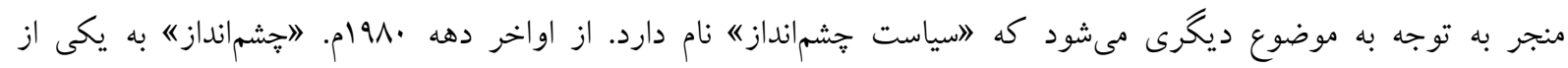

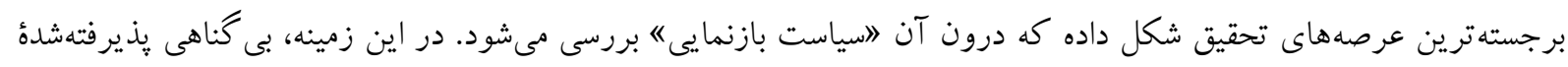

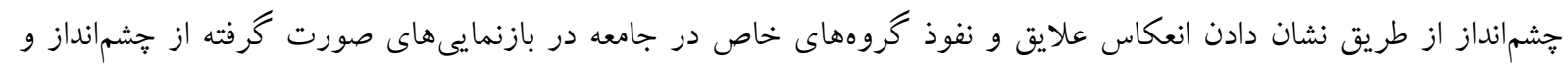

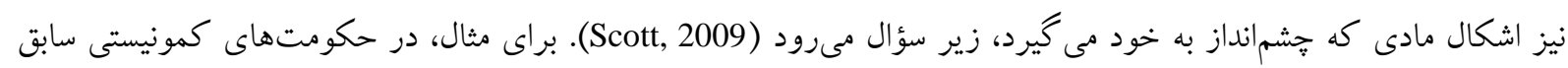

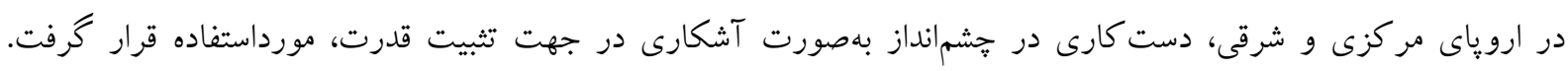




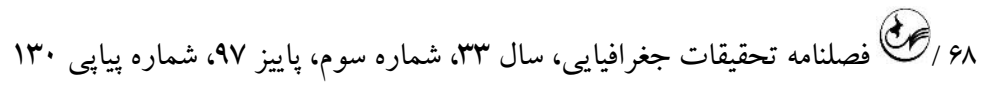
علاوه بر استفاده از نماد ستارهسرخ كمونيسم بر روى ساختمانهاى عمومى، تنديسهاى متعددى از لنين و ساير رهبران ملى در

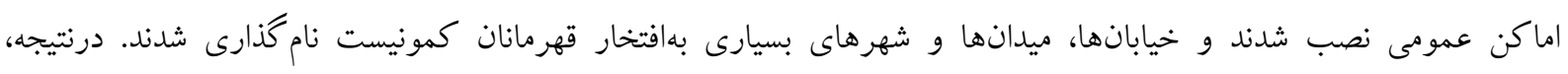
جشمانداز، به عامل يادآورى قدرت كمونيستى به عموم تبديل شد (Jones et al., 2007).

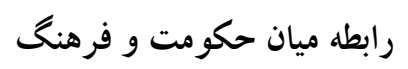

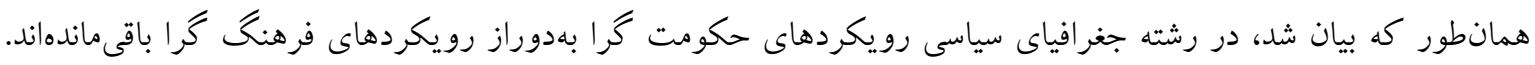

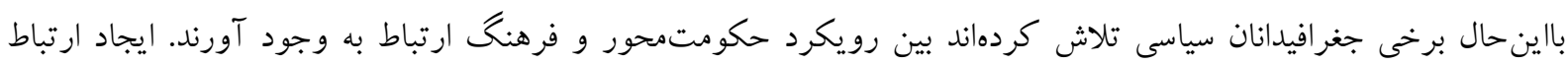

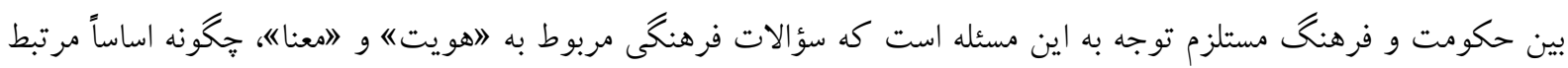

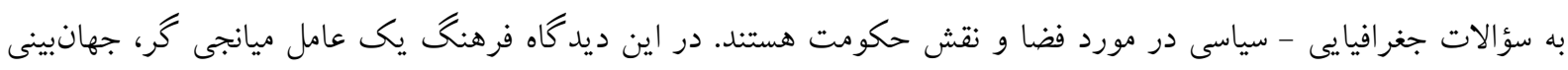

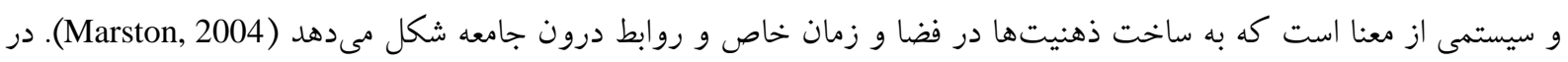

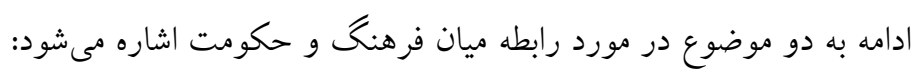

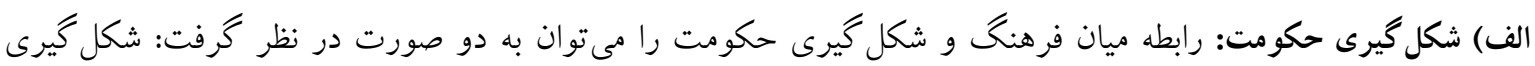

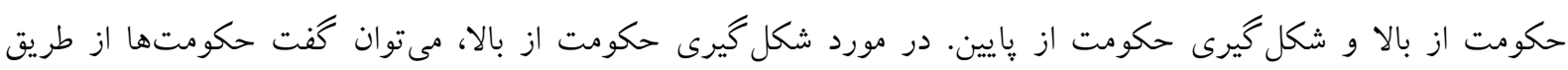

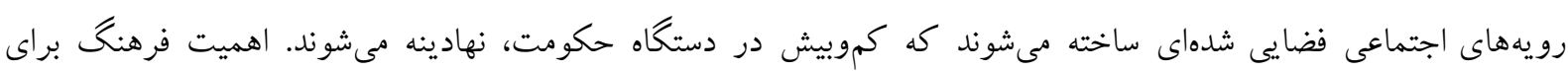

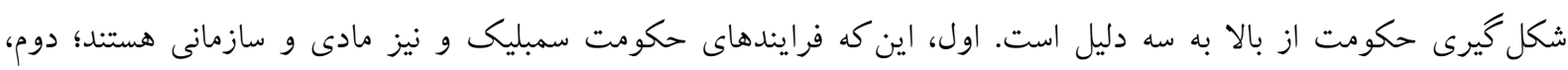

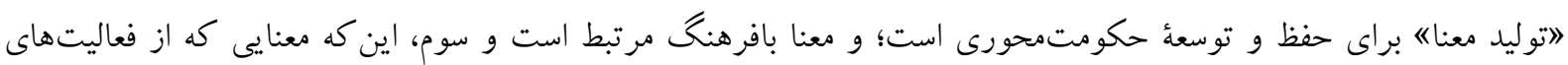

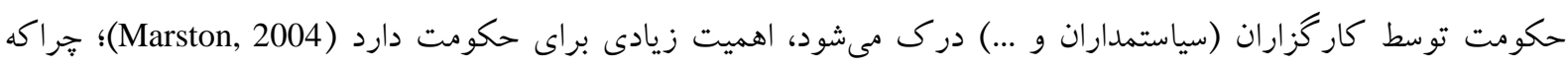

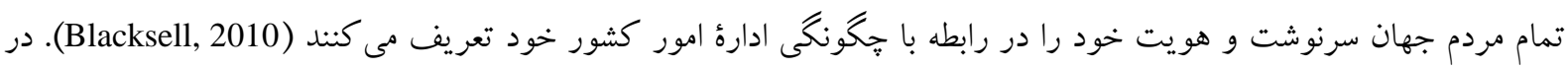

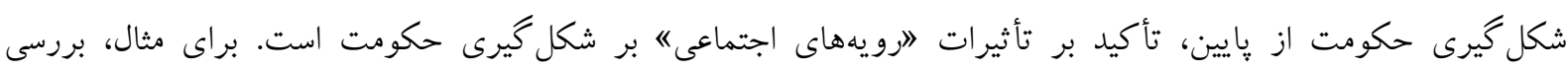

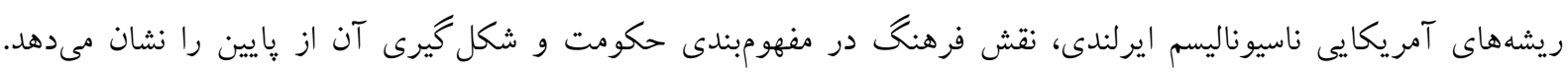

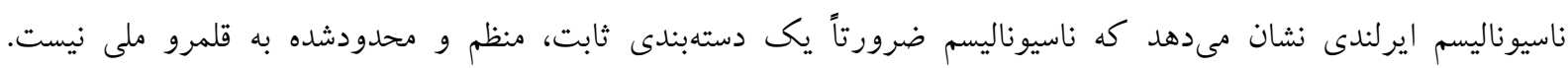

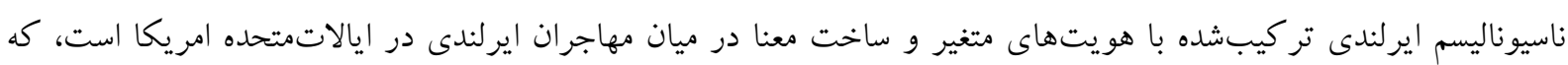

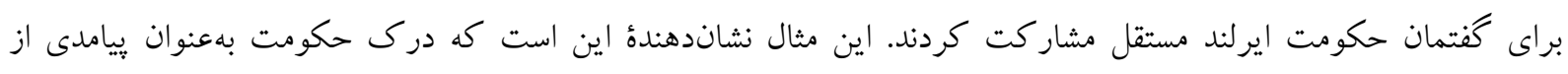

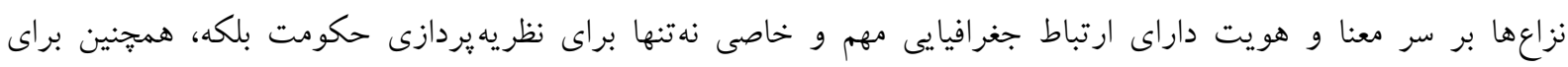

مقاومت و تغيير است (Marston, 2004).

ب) سياست فرهنكى: حكومتها داراى كار كرد فرهنگى هستند و براى رسيدن به اهداف خود ناكزير به اتخاذ يك سياست

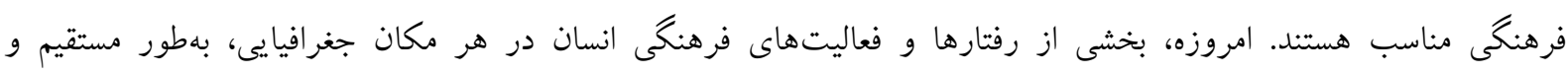

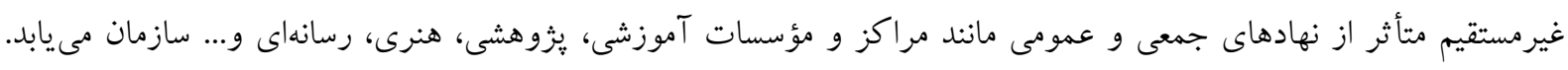

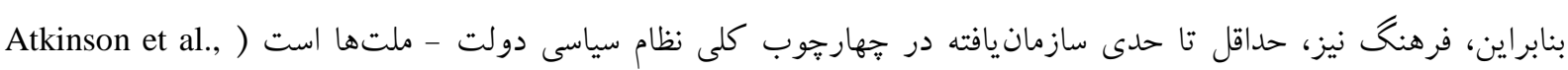

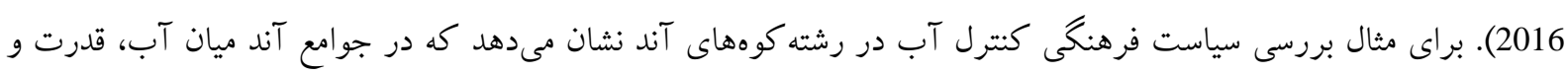

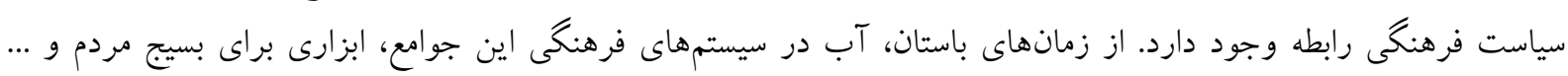

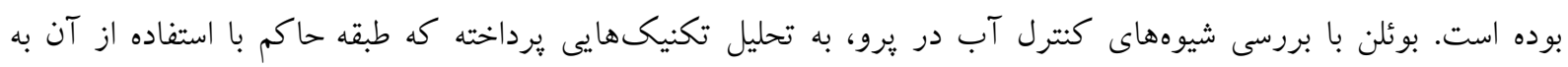

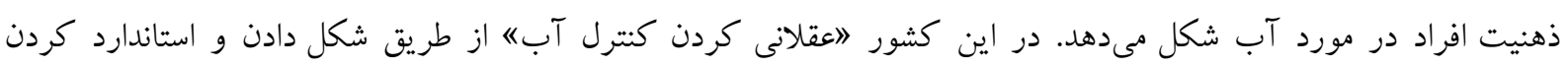

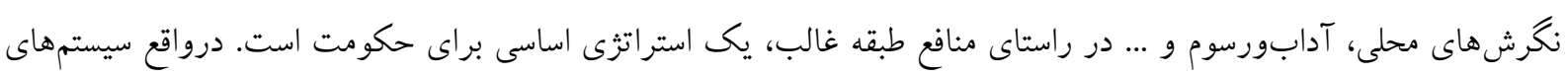


آبيارى در يرو بيش از اين كه سيستمهاى مديريتى باشند، اسازهاى سياسى و فرهنكى" هستند و مسائلى مانند تعريف حقوق

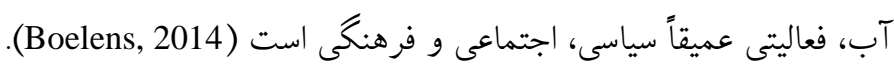

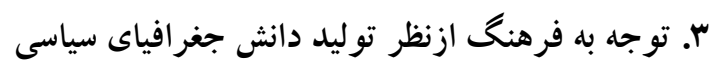

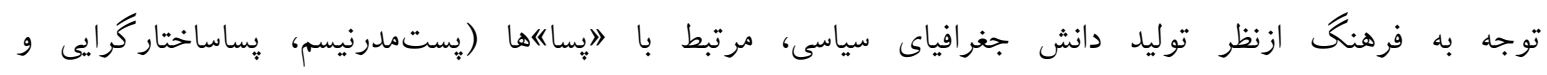

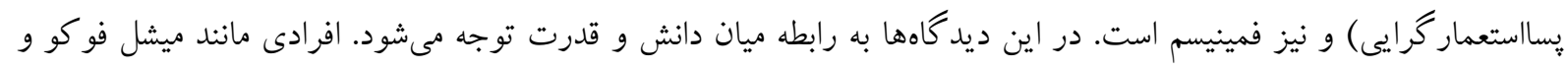

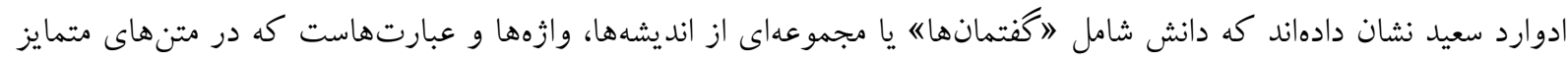

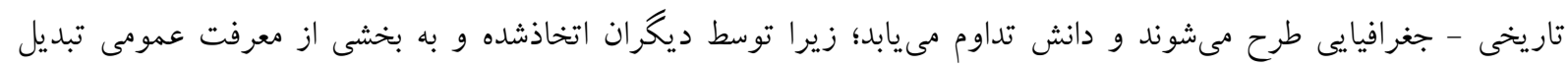

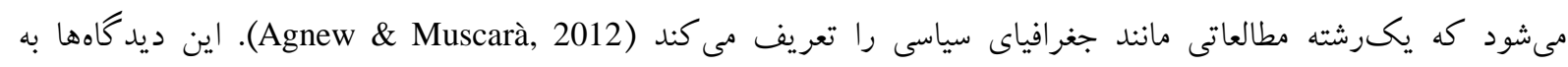

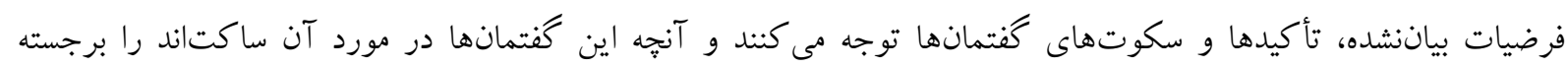

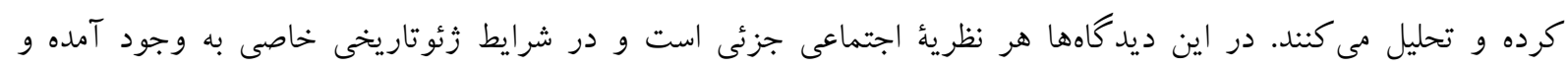

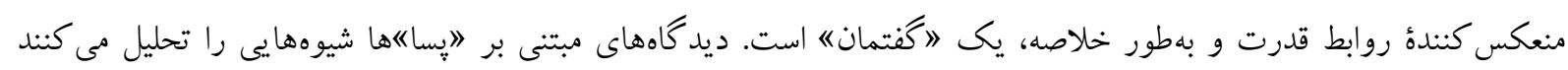

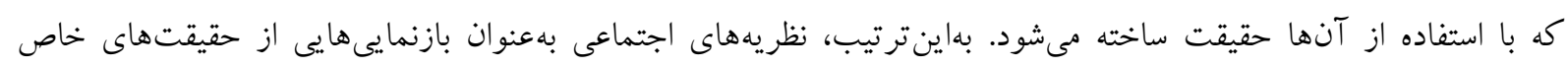

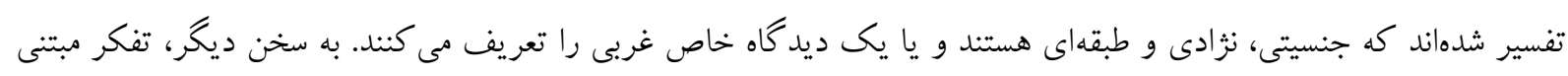

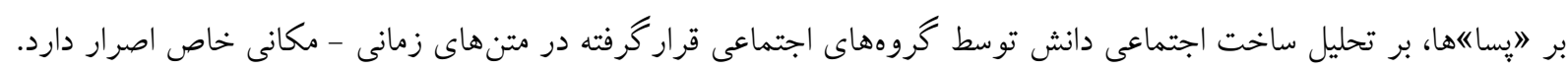

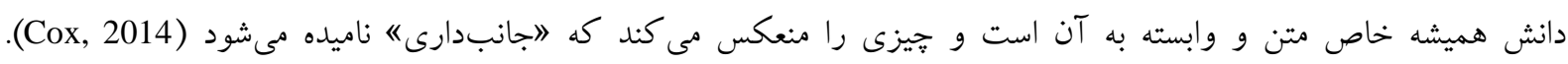

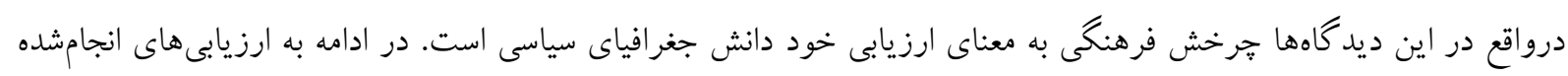

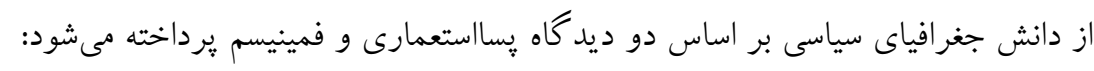

\section{ديد كاه بِاستعمارى}

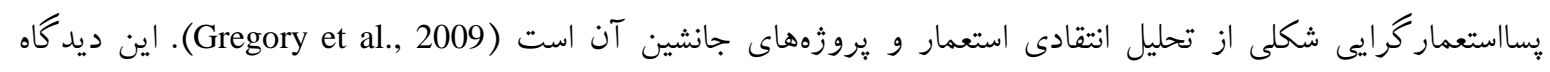

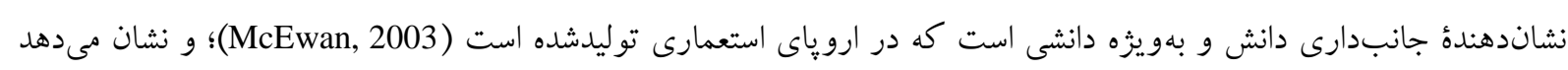

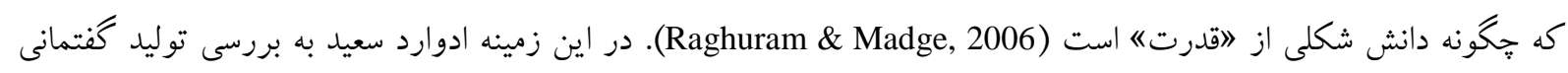

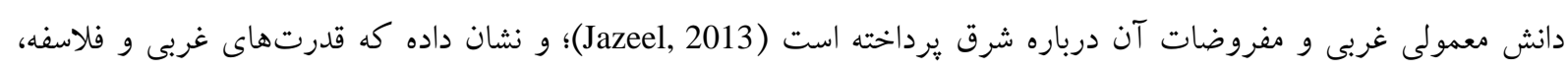

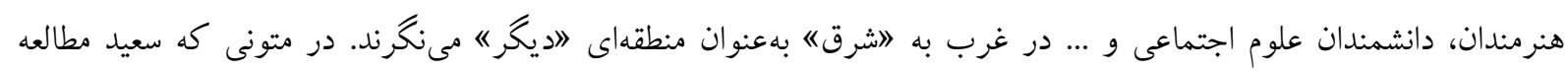

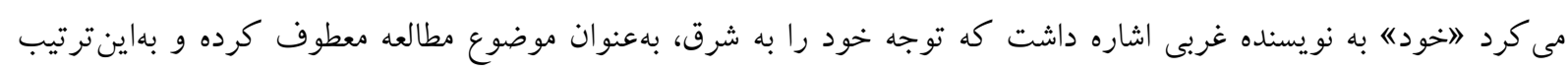

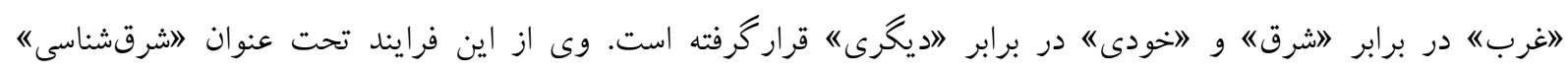

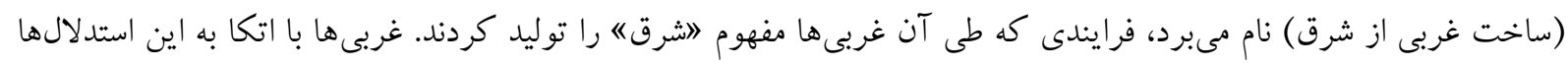

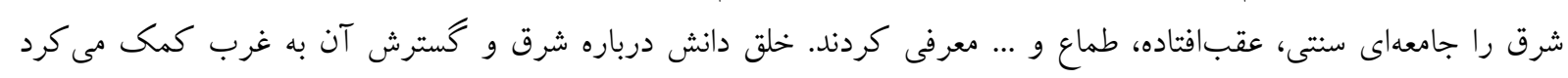

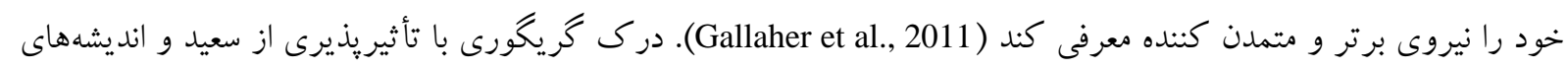
فو كو در مورد روابط متقابل بين دانش، قدرت و فضا، استدلال مى كند كه نقش جغرافيا در مشروعيت ايدئولوزيكى رونى روابط قدرت

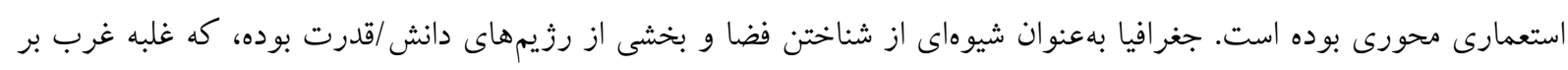

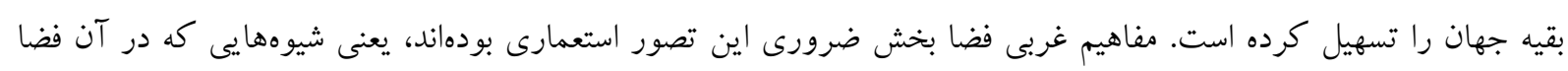

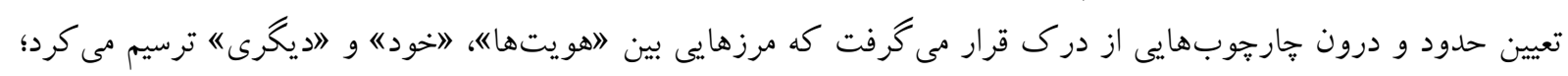

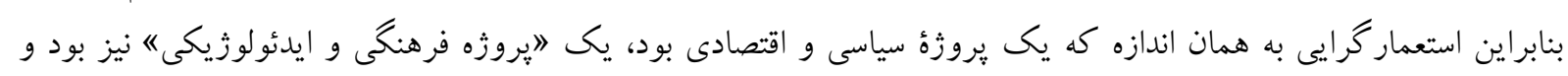




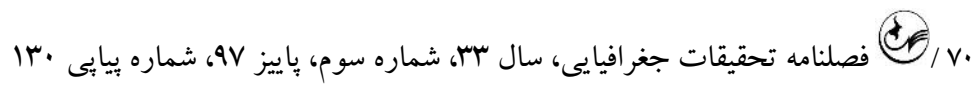

علم جغرافيا عميقاً در شيوههايى كه امروز نيز به آن ادامه مىدهد؛ ارويا محور بوده است (Hubbard \& Kitchin, 2011).

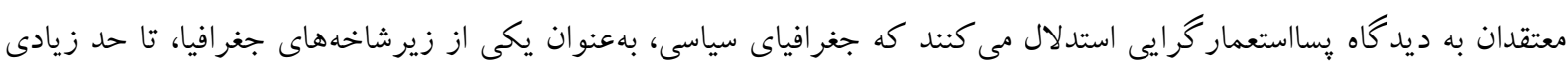

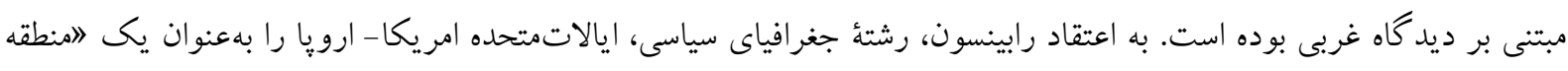

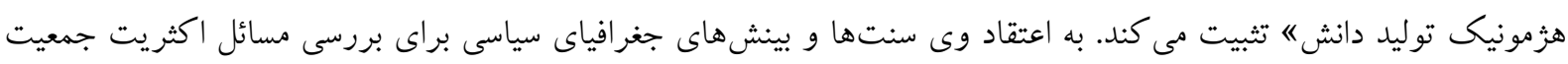

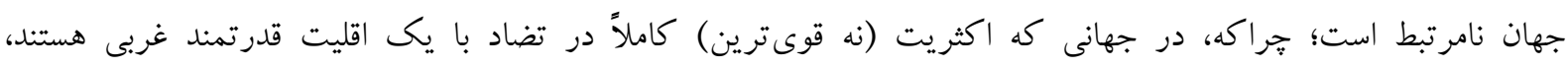

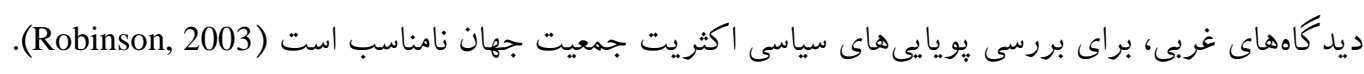

نقدهاى فمينيستى، مانند نقدهاى پِاساستعمارى، دانش و هويت را به هم وابسته و متصل به روابط قدرت مىدانند. درحالى كه

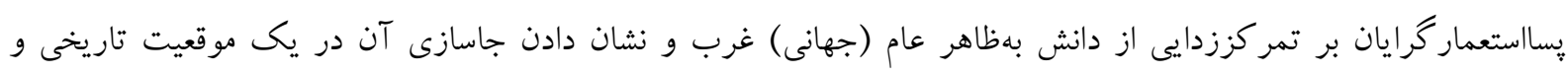

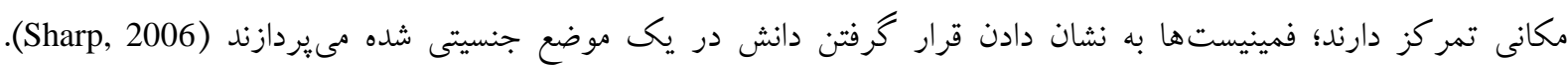

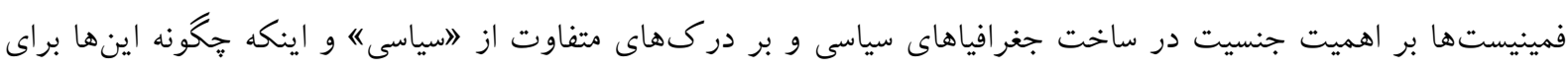

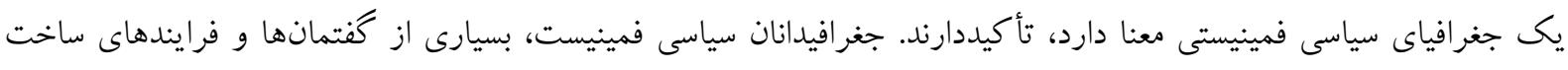

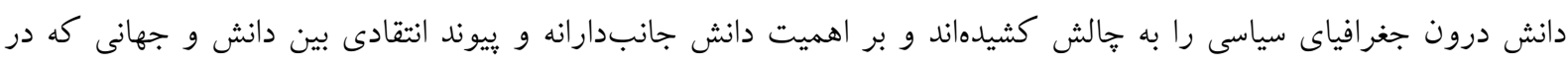

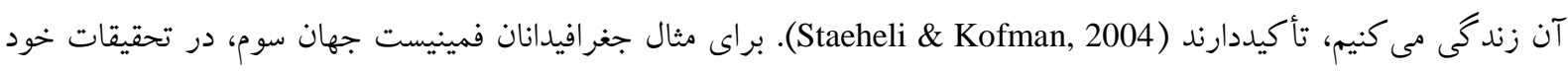

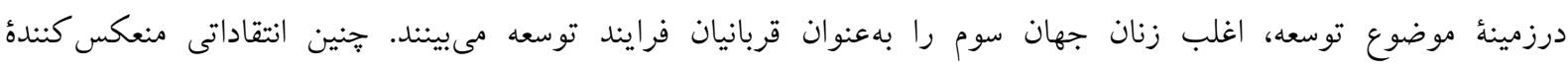

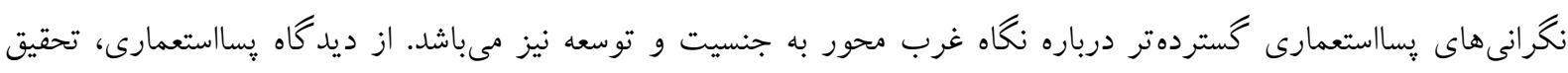

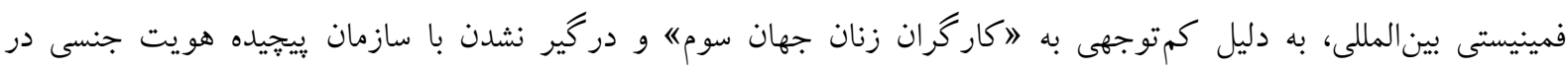

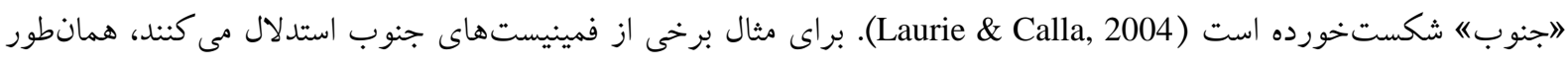

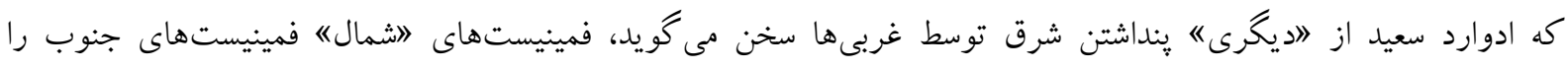

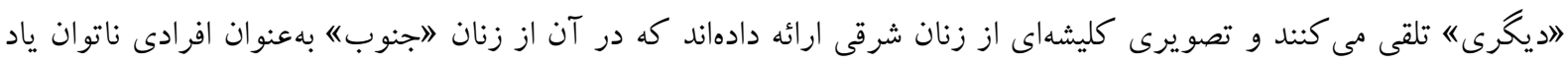

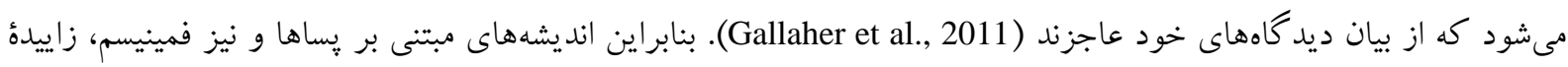

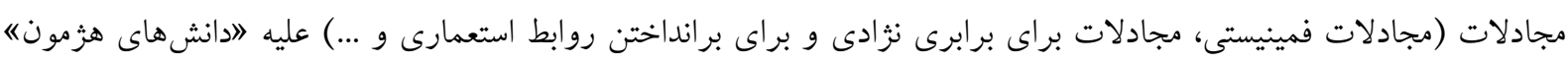

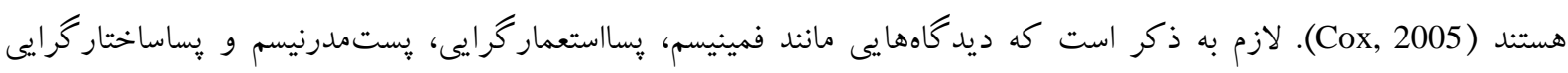

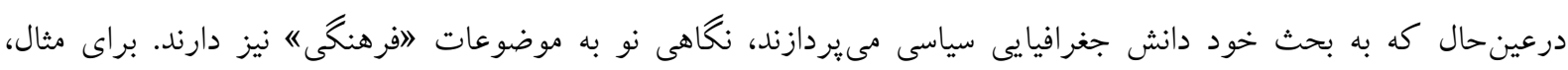

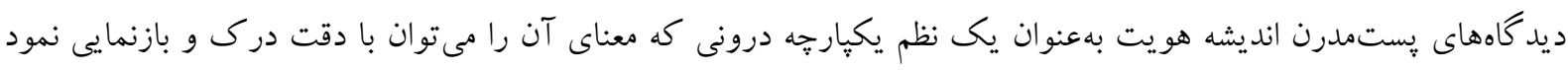

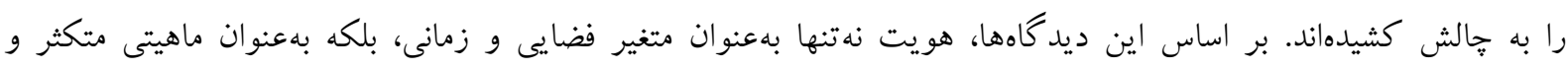

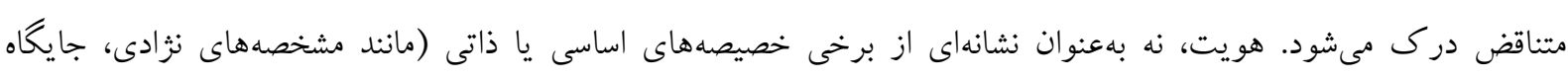

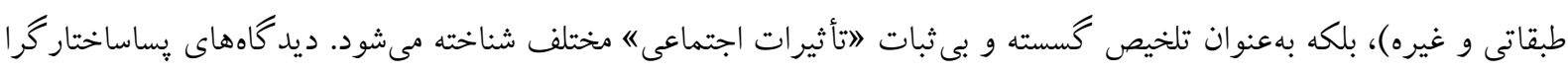

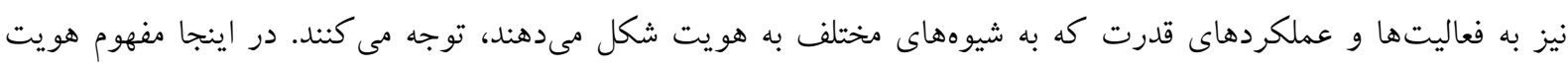

بهنوان يك ساخت " \كتمانى" در نظر كرفته مىشود كه در زبان و از طريق زبان ساخته مىشود (Atkinson et al., 2016).

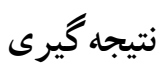

קرخش فرهنكى سه تأثير عمده بر رشته جغرافياى سياسى داشته است. اول، صورتبندى مجدد مفاهيم و موضوعات رشته

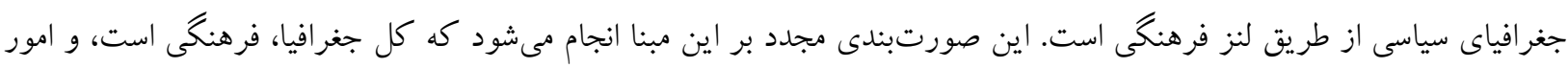




$$
\begin{aligned}
& \text { Vرخ خش فرهنى در جغر افيا و تأثيرات آن بر رشته جغر افياى سياسى } \\
& \text { DOI: } 10.29252 / \text { geores. } 33.3 .58 \\
& \text { و ابسته به فرهنخ، سياسى تلقى مىشوند. در اين زمينه فرهنگ بهعنوان سيستمى از نشانها در نظر گرفته مىشود كه به ساير } \\
& \text { فعاليتها معنا مىدهد و اعمال سياسى بر اساس معنا، نشانها و نمادها درك مىشوند. دوم، تمركز بر موضوعات جديدى كه تا قبل } \\
& \text { از دهه · ^ه ام. موردتوجه نبودند؛ در اين زمينه موضوع عمدهاى كه توجه جغرافيدانان سياسى را به خود جذب نموده عبارت است از } \\
& \text { هويت (مسائلى مانند نقش فضاهاى زندكى روزمره در ساخت هويت سياسى؛ ارتباط ميان هويت و مكان؛ دستكارى معناى } \\
& \text { يديدهاى سياسى - فرهنكى و تأثير آن بر هويت). علاوه بر هويت، موضوع جشمانداز (مسائلى مانند جشمانداز قدرت؛ و سياست } \\
& \text { קشم|نداز)، و رابطه ميان فرهنگ و حكومت (مانند سياست فرهنكى و شكل گيرى حكومت) بيشترين توجهات را به خود جذب } \\
& \text { كرده است. سوم، توجه به فرهنگ ازنظر توليد دانش جغرافياى سياسى بر اساس ديد گاهاى مبتنى بر "يساهاها و فمينيسم. در اين } \\
& \text { زمينه بهنقد و تحليل ساخت اجتماعى دانش جغرافياى سياسى توسط گروههاى اجتماعى قراركرفته در متنهاى زمانى - مكانى خاص } \\
& \text { و فرهنگ هاى خاص يرداخته مىشود و درواقع يك ارزيابى از دانش جغرافياى سياسى بر اساس فرهنگ افرادى كه اين دانش را }
\end{aligned}
$$

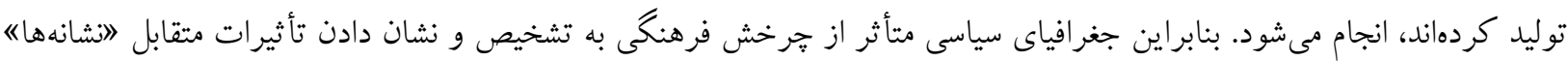

$$
\begin{aligned}
& \text { و انمادهاى" فرهنكى از يكىو و 》اعمال سياسى" از سوى ديخر مى يردازد. در اين زمينه بهويزه بر 》امعنا《 و نزاع بر سر معنا } \\
& \text { تمر كز مىشود. مفاهيم نشانه، نماد، معنا، كفتمان، بازنمايى، روزمره، هويت و تفاوت در محور جغرافياى سياسى متأثر از خرخش } \\
& \text { فرهنگ قرار دارند. } \\
& \text { سهم نويسند گان: فاطمه سادات ميراحمدى (نويسندهُ اول، مسئول)، يزوهشكر اصلى ( •ع ٪)؛ عباس احمدى (نويسنده دوم)، }
\end{aligned}
$$

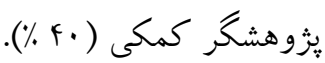

$$
\begin{aligned}
& \text { منابع و مآخذ }
\end{aligned}
$$

Agnew, J. A., \& Muscarà, L. (2012). Making political geography (Second ed.). New York: Rowman \& Littlefield Publishers.

Atkinson, D., Jackson, P., Sibley, D., \& Washbourne, N. (2016). Cultural geography: A critical dictionary of key concepts (M. Badiee Azandahi, F. Mirahmadi, \& E. Yari, Trans.). Tehran: Entekhab.

Badiee Azandahi, M., \& Mirahmadi, F. S. (2016). Emerging issues and perspectives in boundary studies. Human Geography research Quarterly, 48(3), 541-555. [DOI:10.22059/jhgr.2016.56832]. (Persian)

Bell, D. (2009). Cultural studies and human geography. In R. Kitchin \& N. Thrift (Eds.), International Encyclopedia of Human Geography (pp. 437-441). Oxford: Elsevier.

Blacksell, M. (2010). Political geography (M. R. Hafeznia, A. Abdi, H. Rabiee, \& A. Ahmadi, Trans.). Tehran: Entekhab. (Persian)

Boelens, R. (2014). Cultural politics and the hydrosocial cycle: Water, power and identity in the andean highlands. Geoforum, 57, 234-247. [DOI:10.1016/j.geoforum.2013.02.008]

Cox, K. R. (2005). Political geography: Critical concept in the social sciences (Vol. 3). London and NewYork: Routledge.

Cox, K. R. (2014). Making human geography (First ed.). New York: The Guilford Press.

Dodds, K. (2011). Geopolitics: a very short introduction (Z. Pishgahifard \& M. Zohdi Goharpour, Trans.). Tehran: Green Olives. (Persian)

Fayyaz, E., Sarfaraz, H., \& Ahmadi, A. (2011). Semiotics of cultural landscapes in cultural geography; a conceptual strategy for the understanding and discovery of meaning. Cultural Research Quarterly, 4(4), 91-116. (Persian)

Fincher, R. (2004). From dualisms to multiplicities: Gendered political practices. In L. Staeheli, E. Kofman, \& L. Peake (Eds.), Mapping Women, Making Politics (pp. 49-70). New York \& London: Routledge.

Flint, C. (2011). An introduction to geopolitics (M. B. Ghhalibaf \& M. H. Pouyandeh, Trans.). Tehran: Ghomes. (Persian)

Gallaher, C., Dahlman, C. T., Gilmartin, M., Mountz, A., \& Shirlow, P. (2011). Key concepts in political geography (M. H. Nami \& A. Mohamadpoor, Trans.). Tehran: Green Zeytoon Publication. (Persian)

Gibson, C., \& Waitt, G. (2009). Cultural geography. In R. Kitchin \& N. Thrift (Eds.), International Encyclopedia of Human Geography (pp. 411-424). Oxford: Elsevier.

Gregory, D., Johnston, R., Pratt, G., Watts, M., \& Whatmore, S. (2009). The dictionary of human geography (5th ed.). Malden: Wiley Blackwell. 


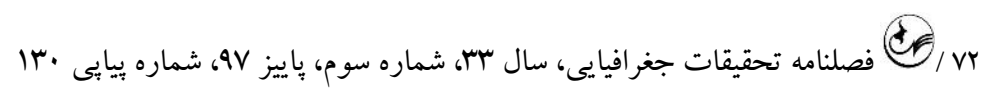

Hubbard, P., \& Kitchin, R. (Eds.). (2011). Thinkers on space and place (Second ed.). London: SAGE Publication Inc.

Jazeel, T. (2013). Postcolonialism. In N. C. Johnson, R. H. Schein, \& J. Winders (Eds.), The Wiley-Blackwell companion to cultural geography (First ed., pp. 17-22). Oxford: John Wiley \& Sons, Ltd.

Jones, M., Jones, R., \& Woods, M. (2007). An introduction to political geography (Z. Pishgahifard \& R. Akbari, Trans.). Tehran: Tehran University Press. (Persian)

Jones, R. (2008). Categories, borders and boundaries. Progress in Human Geography, 33(2), $174-189$. [DOI:10.1177/0309132508089828]

Kobayashi, A. (2009). Representation and re-presentation. In R. Kitchin \& N. Thrift (Eds.), International Encyclopedia of Human Geography (pp. 347-350). Oxford: Elsevier.

Laurie, N., \& Calla, W. P. (2004). Development, postcolonialism, and feminist political geography. In L. Staeheli, E. Kofman, \& L. Peake (Eds.), Mapping Women, Making Politics (pp. 99-112). New York \& London: Routledge.

Marston, S. A. (2004). Space, culture, state: uneven developments in political geography. Political Geography, 23(1), 1-16. [DOI:10.1016/j.polgeo.2003.09.006]

McEwan, C. (2003). Material geographies and postcolonialism. Singapore Journal of Tropical Geography, 24(3), 340-355. [DOI:10.1111/1467-9493.00163]

Minca, C. (2009). Postmodernism/postmodern geography. In R. Kitchin \& N. Thrift (Eds.), International Encyclopedia of Human Geography (pp. 363-372). Oxford: Elsevier.

Mirheidar, D., \& Mirahmadi, F. M. (2016). Evolution of ideas in political geography. Tehran: University of Tehran Press. (Persian)

Newman, D. (2006). Boundaries. In J. A. Agnew, K. Mitchell, \& G. Toal (Eds.), A companion to political geography (Third ed., pp. 123-127). Malden: Blackwell Publishing.

Ó Tuathail, G. (2000). The postmodern geopolitical condition: States, statecraft, and security at the millennium. Annals of the Association of American Geographers, 90(1), 166-178. [DOI:10.1111/0004-5608.00192]

Paasi, A. (2009). Political boundaries. In R. Kitchin \& N. Thrift (Eds.), International Encyclopedia of Human Geography (pp. 217-227). Oxford: Elsevier.

Painter, J. (1995). Politics, geography and 'political geography': A critical perspective. London: Hodder \& Stoughton.

Passi, A. (2003). Boundaries in a globalizing world. In K. Anderson, M. Domosh, S. Pile, \& N. Thrift (Eds.), Hand Book of Cultural Geography (pp. 462-472). London: Sage Publication.

Philo, C. (2009). Cultural turn. In R. Kitchin \& N. Thrift (Eds.), International Encyclopedia of Human Geography (pp. 442-450). Oxford: Elsevier.

Power, M., \& Campbell, D. (2010). The state of critical geopolitics. Political Geography, 29(5), $243-246$. [DOI:10.1016/j.polgeo.2010.06.003]

Raghuram, P., \& Madge, C. (2006). Towards a method for postcolonial development geography? Possibilities and challenges. Singapore Journal of Tropical Geography, 27(3), 270-288. [DOI:10.1111/j.14679493.2006.00262.x]

Robinson, J. (2003). Political geography in a postcolonial context. Political Geography, 22(6), 647-651. [DOI:10.1016/S0962-6298(03)00072-6]

Scott, H. V. (2009). Representation, politics of. In R. Kitchin \& N. Thrift (Eds.), International Encyclopedia of Human Geography (pp. 351-356). Oxford: Elsevier.

Sharp, J. (2004). Doing feminist political geographies. In L. Staeheli, E. Kofman, \& L. Peake (Eds.), Mapping Women, Making Politics (pp. 87-98). New York \& London: Routledge.

Sharp, J. P. (2006). Feminist and postcolonial engagement. In J. A. Agnew, K. Mitchell, \& G. Toal (Eds.), A companion to political geography (Third ed., pp. 59-74). Malden: Blackwell publishing.

Sidaway, J. D. (1997). Politics, geography and 'political geography': A critical perspective: Joe Painter, Arnold, London, 1995, 206pp. Political Geography, 16(1), 89-91. [DOI:10.1016/S0962-6298(97)83031-4]

Smith, J. M. (2009). Humanism/Humanistic Geography. In R. Kitchin \& N. Thrift (Eds.), International Encyclopedia of Human Geography (pp. 239-250). Oxford: Elsevier.

Staeheli, L. A., \& Kofman, E. (2004). Mapping gender, making politics: Toward feminist political geographies. In L. Staeheli, E. Kofman, \& L. Peake (Eds.), Mapping women, making politics: Feminist perspectives on political geography (pp. 1-14). New York \& London: Routledge.

Toal, G., \& Agnew, J. (2003). Political geographies, geopolitics and culture. In M. Anderson, M. Domosh, S. Pile, \& N. Thrift (Eds.), Hand Book of Cultural Geography (pp. 455-461). London: Sage Publication.

Van Houtum, H. (2005). The geopolitics of borders and boundaries. Geopolitics, 10(4), 672-679. [DOI:10.1080/14650040500318522] 